\title{
The geometry of mortality change: Convex hulls for demographic analysis
}

\author{
Audrey F. Lai* (i) https://orcid.org/0000-0003-4794-4781 \\ Andrew Noymer ${ }^{+}$(D) https://orcid.org/0000-0003-2378-9860 \\ Tsuio Tai ${ }^{\ddagger}$ (D) https://orcid.org/0000-0003-4402-1308
}

15 July 2019

This is the green OA version. The published version - which is also open access - is available at: https://ojs.uclouvain.be/index.php/Quetelet/article/view/20873

or at the DOI in the page heading.

\section{Abstract}

We introduce convex hulls as a data visualization and analytic tool for demography. Convex hulls are widely used in computer science, and have been applied in fields such as ecology, but are heretofore underutilized in population studies. We briefly discuss convex hulls, then we show how they may profitably be applied to demography. We do this through three examples, drawn from the relationship between child and adult mortality ( ${ }_{5} q_{0}$ and ${ }_{45} q_{15}$ in life table notation). The three examples are: (i) sex differences in mortality; (ii) period and cohort differences and (iii) outlier identification. Convex hulls can be useful in robust compilation of demographic databases. Moreover, the gap/lag framework for sex differences or period/cohort differences is more complex when mortality data are arrayed by two components as opposed to a unidimensional measure such as life expectancy. Our examples show how, in certain cases, convex hulls can identify patterns in demographic data more readily than other techniques. The potential applicability of convex hulls in population studies goes beyond mortality.

Keywords: Exploratory data analysis; convex hulls; mortality; data quality.

${ }^{*}$ Program in Bioinformatics, Northeastern University, Boston, Massachusetts, USA

${ }^{\dagger}$ Department of Population Health and Disease Prevention, University of California, Irvine, USA. To whom correspondence should be addressed: noymercuci .edu

‡Department of Sociology, National Taipei University, San Shia, Taiwan 


\section{Introduction}

We propose convex hulls as a technique of demographic analysis, illustrated by three examples. The convex hull of a set of points is the region defined by a perimeter in which the line segment connecting any two points lies on or inside the perimeter. ${ }^{1}$ An informal heuristic is that if a set of points consists of pegs in a board, the convex hull is the shape of a rubber band stretched around the outermost pegs, such that all the pegs are enclosed by the band. Figure 1 is an example: the data are seven random points in a plane (1A). There are a number of ways to draw a perimeter, of which one is shown (1B). The unique convex hull is illustrated as a white polygon (1C). The dashed line segments (1D) demonstrate why the region in 1B is not convex. Line segments connecting any two points in the data may be an edge of the convex hull, or interior, but cannot pass outside of it. Convex hulls exist in all dimensions: as a range (line segment) for unidimensional data, as polygons in $\mathbb{R}^{2}\left(“ 2 \mathrm{D}^{\prime}\right)$, as polyhedra in $\mathbb{R}^{3}\left(\right.$ " $\left.3 \mathrm{D}^{\prime \prime}\right)$, and as polytopes in higher dimensional spaces. We only consider applications in two dimensions.

Calculating a convex hull of multidimensional data is analogous to sorting unidimensional data; it determines the boundaries, which in the univariate case is the minimum and maximum (Barnett 1976). For crossclassified data, the $x$ range is the orthogonal projection of the convex hull onto the $x$-axis, similarly with the $y$ data, and so on for higher dimensions. Using convex hulls in data analysis is not a new idea. "Tukey peeling", also called convex peeling (Hodge and Austin, 2004), has some similarities to our third application. As an alternative to Winsorization (Tukey, 1962), Tukey peeling entails obtaining robust estimates in multivariate analysis by

\footnotetext{
${ }^{1}$ For a concise and more formal definition, cf. Kemeny and Snell (1962, p. 123); also Kemeny et al. (1966), pp. 312-3: "A convex set $C$ is a set such that whenever $u$ and $v$ are points of $C$, the entire line segment between $u$ and $v$ also belongs to $C$." A two-dimensional convex hull consists of vertices, edges that connect these vertices, and the (interior) convex polygon defined by the edges; see figure 1 .
} 


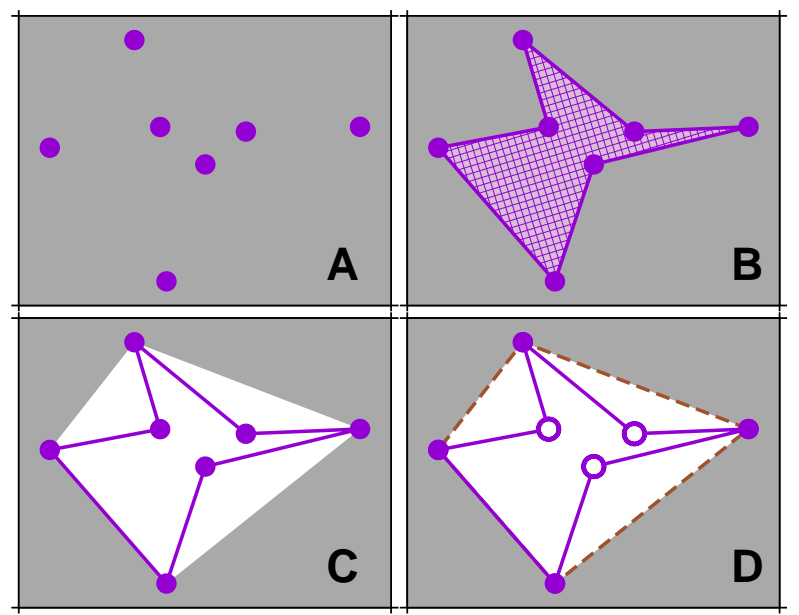

Figure 1: A: seven randomly-distributed points in a plane. B: one possible perimeter and its (non-convex) polygon (shaded). C: the convex hull, in white. D: dashed line segments illustrate non-convexity of the original perimeter. Vertices of the convex hull are shown as filled disks, while original points that are members of the convex set (i.e., the white region), but are not hull vertices, are shown as open circles.

removing (the vertices of) one or more convex hulls from the data, preanalysis. It originated in the early 1970s (Huber, 1972), and is further elaborated in Tukey (1975) and Bebbington (1978).

The properties of convex hulls of data are fairly well understood, provided the data are reasonably well behaved. There is a large literature here; see, f.e., Efron (1965), Eddy (1980), Aldous et al. (1991), Blackwell (1992), Snyder and Steele (1993), Hueter (1994), Massé (2000), Suri et al. (2013). To the best of our knowledge, these techniques have not been applied in depth in demography. Appearances of "convex hull" in the demographic literature are sparse and arise in conjunction with linear programming solutions (f.e., Georgakis and Tziafetas, 1982), rather than as an analytic tool on its own. Wrigley and Schofield's (1981, p. 247) "demographic terrain" is similar in spirit to convex hull analysis as we conceptualize it (see also Gold- 
stone 1986, Galloway 1994). Neighboring academic fields, such as ecology, have used convex hulls more (f.e., Getz and Wilmers 2004, Cornwell et al. 2006). Our three applications illustrate the usefulness of convex hulls to population studies.

\section{Materials and Methods}

Using data on all countries in the Human Mortality Database (HMD) (2017, Barbieri et al. 2015), we analyze life table probabilities of child and adult mortality ( ${ }_{5} q_{0}$ and ${ }_{45} q_{15}$, respectively). Table 1 lists the included countries. Throughout, we refer to cross-classification of child and adult mortality as the mortality relationship, and, as applicable, the mortality hull. We perform three analyses, the first of which compares male and female convex hulls, on a country-by-country basis. The second analysis compares period and cohort data, on a per-country and per-sex basis. The third examines outlier countries in the HMD, in which we systematically delete one country at a time, and quantify how the convex hull changes. Convex hull calculation is well studied (Preparata and Shamos 1985, de Berg et al. 2008), and is available in many software packages. We used IDL ver. 8.6 (Exelis Visual Information Solutions, Inc., Boulder, Colorado, USA).

Figure 2 is an example of the convex hull approach to the mortality relationship, showing the mortality hull, separately by sex, for the entire data set. Individual countries are color-coded, although most of the data are densely clustered and therefore overlapping. Superposed on figure 2 is a more conventional approach, a regression fit of ${ }_{45} q_{15}$ as a quadratic function of ${ }_{5} q_{0}$, along with its $95 \%$ prediction interval. ${ }^{2}$ Near the center of mass, the regression line does a good job of representing the tendency of the mortality relationship.

\footnotetext{
${ }^{2}$ This is wider than the $95 \%$ confidence interval of the regression curve. See, f.e., Snedecor and Cochran (1989), p. 168; DeGroot and Schervish (2002), p. 614; etc.
} 
Table 1: Country list: Start and end years.

\begin{tabular}{|c|c|c|c|c|c|}
\hline \multirow{2}{*}{$\begin{array}{l}\text { HMD } \\
\text { Abbrev. }\end{array}$} & \multirow[b]{2}{*}{ Country } & \multicolumn{2}{|c|}{ Period } & \multicolumn{2}{|c|}{ Cohort } \\
\hline & & start & end & start & end \\
\hline AUS & Australia & 1921 & 2014 & & \\
\hline AUT & Austria & 1947 & 2014 & & \\
\hline BLR & Belarus & 1959 & 2014 & & \\
\hline BEL & Belgium $†$ & 1841 & 2015 & & \\
\hline BGR & Bulgaria & 1947 & 2010 & & \\
\hline CAN & Canada & 1921 & 2011 & & \\
\hline CHL & Chile & 1992 & 2005 & & \\
\hline CZE & Czech Republic & 1950 & 2014 & & \\
\hline DNK & Denmark & 1835 & 2014 & 1835 & 1923 \\
\hline EST & Estonia & 1959 & 2013 & & \\
\hline FIN & Finland & 1878 & 2015 & 1878 & 1924 \\
\hline FRATNP & France* & 1816 & 2014 & 1816 & 1923 \\
\hline DEUTE & E Germany & 1956 & 2013 & & \\
\hline DEUTW & W Germany & 1956 & 2013 & & \\
\hline GRC & Greece & 1981 & 2013 & & \\
\hline HUN & Hungary & 1950 & 2014 & & \\
\hline IRL & Ireland & 1950 & 2014 & & \\
\hline ISL & Iceland & 1838 & 2013 & 1838 & 1922 \\
\hline ISR & Israel & 1983 & 2014 & & \\
\hline ITA & Italy & 1872 & 2012 & 1872 & 1921 \\
\hline JPN & Japan & 1947 & 2014 & & \\
\hline LVA & Latvia & 1959 & 2013 & & \\
\hline LTU & Lithuania & 1959 & 2013 & & \\
\hline LUX & Luxemburg & 1960 & 2014 & & \\
\hline NLD & Netherlands & 1850 & 2012 & 1850 & 1921 \\
\hline NZL-MA & New Zealand (Maori) & 1948 & 2008 & & \\
\hline NZL-NM & New Zealand (Non-Maori) & 1901 & 2008 & & \\
\hline NOR & Norway & 1846 & 2014 & 1846 & 1923 \\
\hline POL & Poland & 1958 & 2014 & & \\
\hline PRT & Portugal & 1940 & 2015 & & \\
\hline RUS & Russia & 1959 & 2014 & & \\
\hline SVK & Slovakia & 1950 & 2014 & & \\
\hline SVN & Slovenia & 1983 & 2014 & & \\
\hline ESP & Spain & 1908 & 2014 & & \\
\hline SWE & Sweden & 1751 & 2014 & 1751 & 1923 \\
\hline CHE & Switzerland & 1876 & 2014 & 1876 & 1923 \\
\hline TWN & Taiwan & 1970 & 2014 & & \\
\hline GBRTENW & U.K./England \& Wales* & 1841 & 2013 & 1841 & 1922 \\
\hline GBR-SCO & U.K./Scotland & 1855 & 2013 & 1855 & 1922 \\
\hline GBR-NIR & U.K./Northern Ireland & 1922 & 2013 & & \\
\hline UKR & Ukraine & 1959 & 2013 & & \\
\hline USA & United States & 1933 & 2015 & & \\
\hline
\end{tabular}


Nonetheless, we think figure 2 is a good illustration of the shortcomings of the parametric curve fitting approach. ${ }^{3}$ Particularly away from the center, and even with the prediction interval, the regression line does not represent the variation of the data as well as the convex hull. This is not surprising: the central tendency - not the variation - is the concern of the regression curve (Mosteller and Tukey, 1977, p. 266). For the males, all of the data outside of the prediction interval, except two points, lie above it. The females show a more standard situation, in which the points outside the $95 \%$ prediction interval are roughly evenly split between above and below. The reason for the male asymmetry is that negative health shocks - especially wars, in the male:female context - are severe and, in period data, sudden. Positive health shocks, on the other hand (f.e., Gorbachev's anti-alcohol campaign, see Bhattacharya et al. 2013) are less common. Sudden policy changes, such as tobacco taxes, typically take time to show their salutary effects. Regardless, it is not ideal that the male data outside the prediction interval lies mostly above it. This points to our endeavor of finding other techniques that might be used.

The geometric (viz., convex hull) approach is not meant to be a replacement for curve fitting, but a complement to it. Nonetheless, in many areas of population studies, convex hulls may better capture the inherent variation of the data, especially in situations where the quantities of interest do not have a homoskedastic relationship. ${ }^{4}$ The logic of our approach is that when comparing the mortality relationship (or any other multivariate classification) of two or more populations, convex hulls are a natural way to see how the data interleave. This approach is superior to comparing the bi-

\footnotetext{
${ }^{3}$ An excellent example of the regression approach to two life table quantities is Woods and Hinde (1987), p. 45.

${ }^{4}$ For quantities sometimes analyzed on log scale (see, f.e., Wilmoth et al. 2012), log the data first, then calculate the hull, not vice versa. Although the logarithmic transformation is monotone, it is not affine, so it need not preserve convexity. The hulls of the log-log mortality relationship behave much in the same way as the ones presented here.
} 

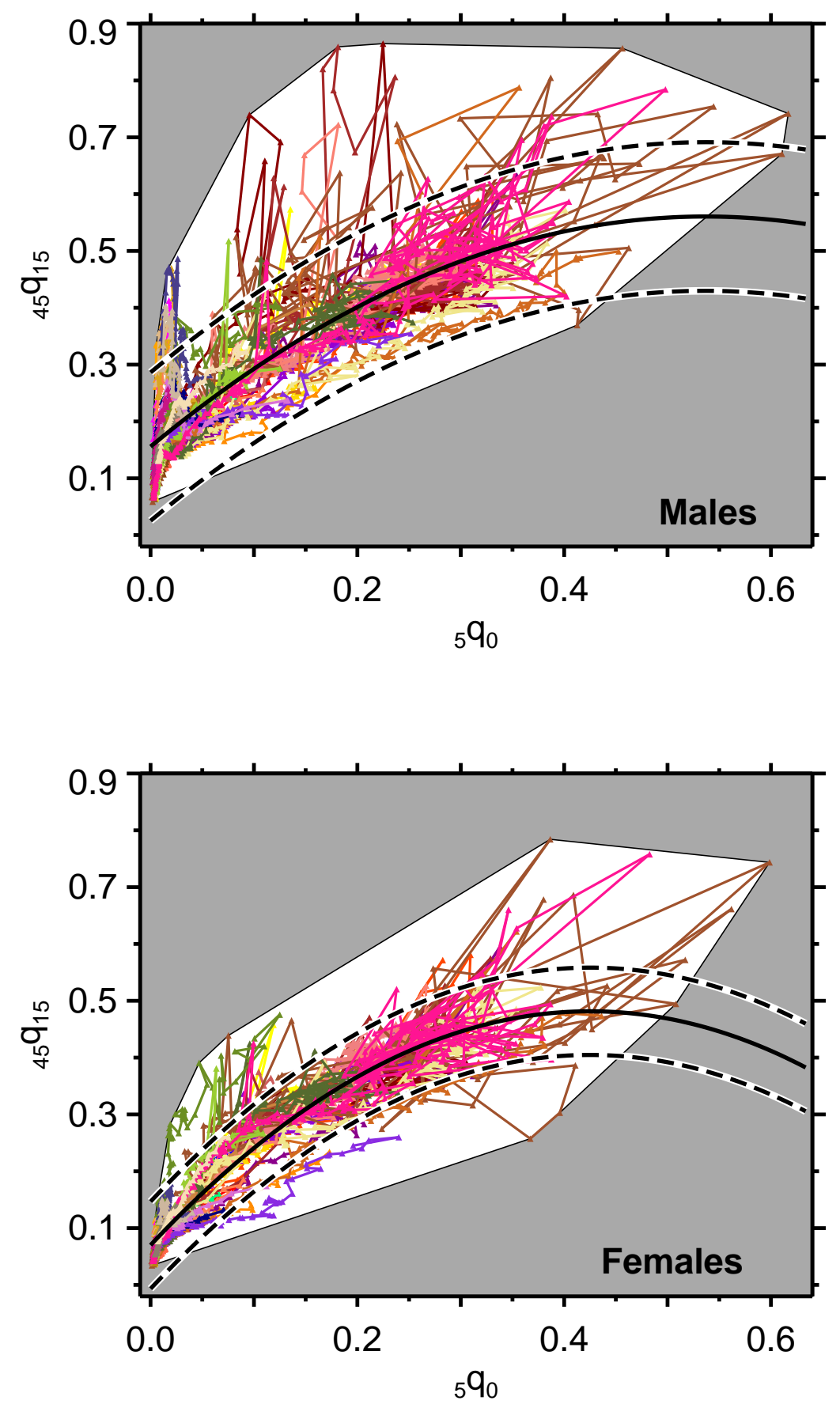

Figure 2: Adult vs child mortality, by sex. With convex hull, and quadratic regression line (solid) and its associated 95\% prediction interval (dashed). Inside the hull, line segments connect chronologically-consecutive points on a per-country basis. 
variate ranges, which would replace the hulls with rectangles of potentially much greater area.

The cross-classification of child and adult mortality - the mortality relationship - has been studied without hulls. In populations with incomplete data, it is common to have only estimates of ${ }_{45} q_{15}$ and ${ }_{5} q_{0}$ (or similar), from which the rest of the life table is imputed (Timæus and Moultrie, 2013). Even without the use of convex hulls, data quality can be assessed by comparing the mortality relationship of a single country to model predictions (Woods 1993, 2000, p. 375; Rao et al. 2005), or to a battery of countries with good data quality (Reniers et al. 2011, Gerland 2014). Examining the mortality relationship (or similar cross classifications of life table quantities) is a staple of methodological work on model life tables (f.e., Coale and Demeny 1983, Murray et al. 2003, Wilmoth et al. 2012). Demeny and Gingrich (1967) look at ${ }_{5} q_{0}$ and $e(5)$, which is similar in spirit. Convex hull analysis permits quantification of these comparisons.

\section{Results}

\section{i) Sex differences}

Much of population studies concerns time series of demographic phenomena (life expectancy, total fertility rate, etc.). Gaps and lags is one way to conceptualize the movement of two time series of the same quantity for related populations. Figure 3 illustrates this for American males and females; each panel shows a different mortality measure: figure $3 \mathrm{~A}$, child mortality $\left({ }_{5} q_{0}\right)$; figure $3 \mathrm{~B}$, adult mortality $\left({ }_{45} q_{15}\right)$. The separations between the male and female series can be regarded as a gap (along the vertical axis, shown in white), or as a lag (along the horizontal axis, shown in black). In 1945 , the male-female gap in child mortality was 11 per thousand. Or, one could say that the males would take 4.5 more years to achieve the equivalent ${ }_{5} q_{0}$ 


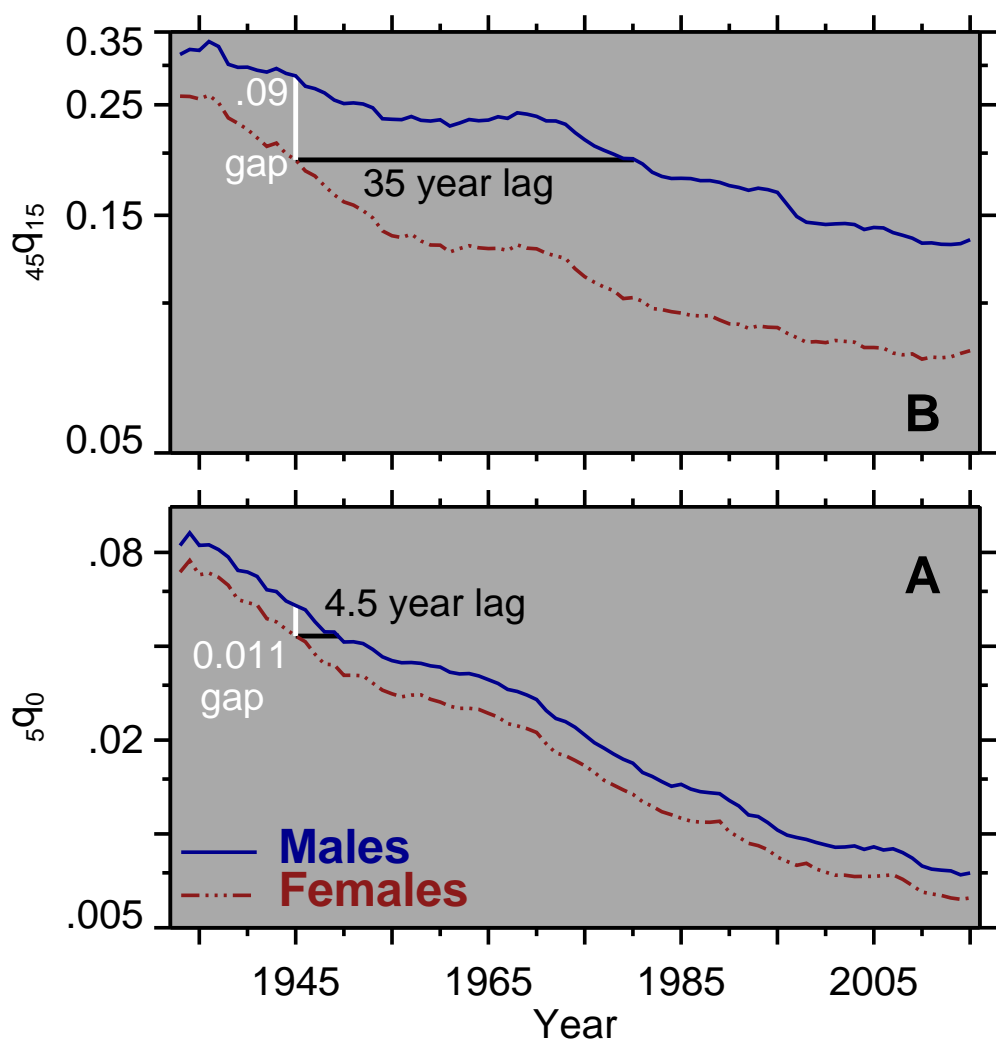

Figure 3: Sex differences in mortality, gaps and lags perspective. Female advantage, which is the typical, can be viewed as a period gap (vertical axis), or as a lag (horizontal axis) of males. A: ${ }_{5} q_{0}$, child mortality; B: ${ }_{45} q_{15}$, adult mortality. All data from HMD, for the United States. 
as females in 1945 (a lag). Goldstein and Wachter (2006) formalized the gaps and lags framework, using periods and cohorts as the population dichotomy. As we show here without the formalism, this framework also applies to sex differences.

In the univariate time series approach, gaps can be recast as lags. In terms of mortality decline, males and females plough the same ground, but the female mortality advantage (or gap) means that males do so later. Figure 4 shows the convex hull approach to this problem. Consider first the "ISL" panel, for Iceland. We see exactly the phenomenon of males following in the path of females: the hulls are substantially overlapping. Given that the time period is the same for each sex, we should not expect total overlap. Males begin the series with mortality levels higher than seen in females, and females end the series with lower mortality than seen in males for the same time interval. Thus, we expect two regions, at opposite ends of the space, where the hulls do not overlap. This is precisely what the convex hull plot for Iceland shows.

For the United States (figure 4, "USA"), the convex hull analysis reveals a different pattern. Unlike the univariate time series in figure 3, the males' mortality relationship does not follow in the footsteps of the females'. The convex hulls are disjoint, indicating that males and females are not playing follow the leader, but are taking different paths. The disparate lags in figure 3 (i.e., 35 years for adult mortality but only 4.5 years for child mortality) drive the disjointness of the male and female hulls. The long lag for the adult mortality data is thought to be due principally to behavioral influences, especially tobacco use (Pampel 2002). While a careful read of figure 3 would allow one to predict the divergent paths over time, the hull approach reveals this much more clearly. It is expected that the sex-specific hulls will eventually overlap as the mortality relationship evolves, given that zero is a floor for the mortality data $\left({ }_{5} q_{0},{ }_{45} q_{15}\right)$. 

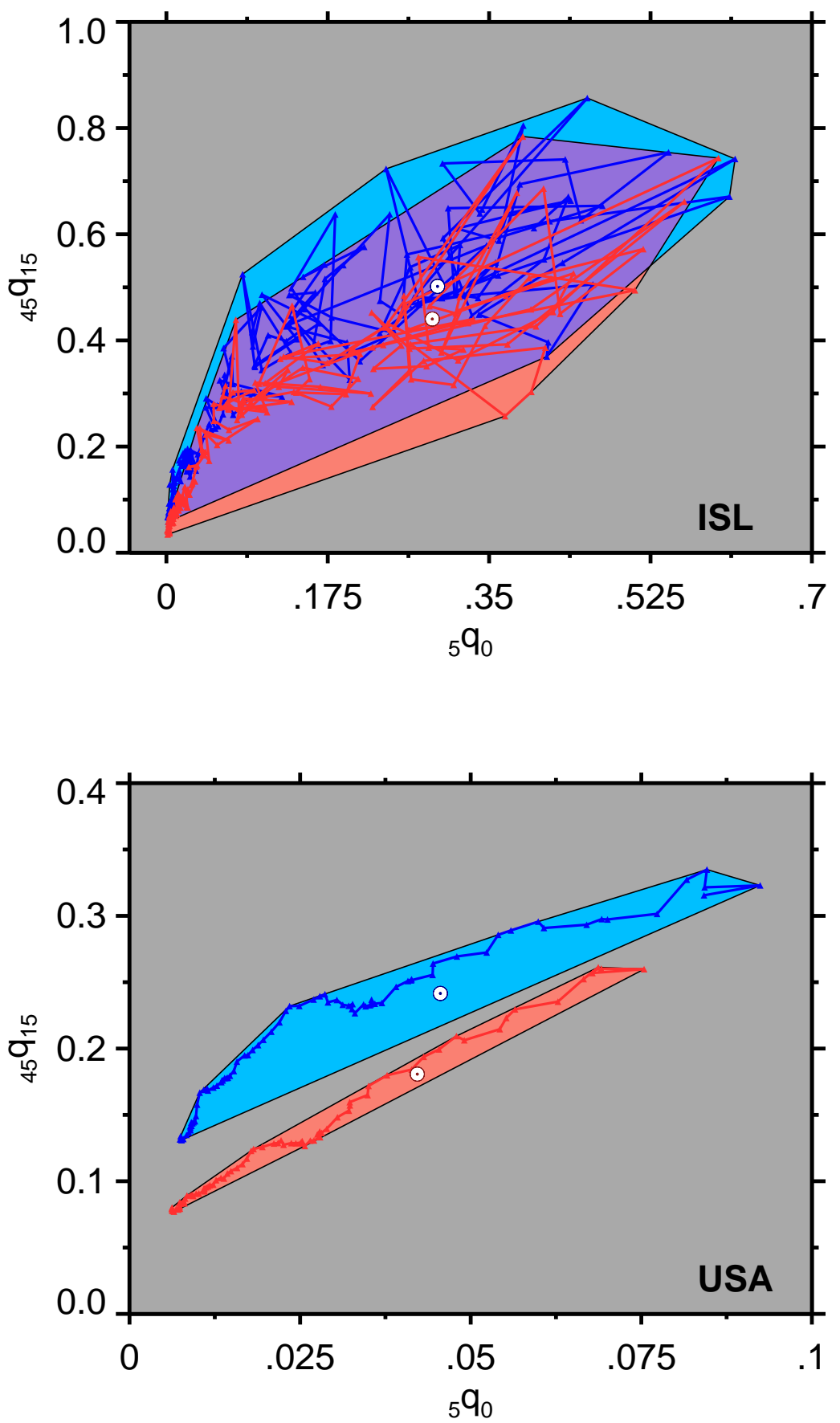

Figure 4: Male (blue) and female (red) sex-specific hulls for the mortality relationship, Iceland (ISL) and United States (USA). Overlap shown in purple. Bullseyes mark the centroids of the hulls. 
Table 2: Male and female hulls: Descriptive and comparative statistics.

\begin{tabular}{|c|c|c|c|c|c|c|c|c|c|}
\hline \multirow[b]{3}{*}{ Country } & \multicolumn{2}{|c|}{ Female to male } & \multirow{2}{*}{\multicolumn{2}{|c|}{$\begin{array}{l}\text { Intersection } \\
\text { area as \% of }\end{array}$}} & \multirow{2}{*}{\multicolumn{2}{|c|}{$\begin{array}{l}\% \text { of points in } \\
\text { intersection }\end{array}$}} & \multirow{3}{*}{$\begin{array}{l}\text { Euclidean } \\
\text { dist. btwn. } \\
\text { centroids }\end{array}$} & \multirow{2}{*}{\multicolumn{2}{|c|}{$\begin{array}{l}\text { Centroid in } \\
\text { opposite hull? }\end{array}$}} \\
\hline & \multirow{2}{*}{$\begin{array}{l}\text { Area } \\
\text { Ratio }\end{array}$} & \multirow{2}{*}{$\begin{array}{l}\text { Diameter } \\
\text { Ratio }\end{array}$} & & & & & & & \\
\hline & & & M & $\mathrm{F}$ & $\mathrm{M}$ & $\mathrm{F}$ & & $\mathrm{M}$ & $\mathrm{F}$ \\
\hline & (A) & (B) & (C) & (D) & (E) & (F) & $(G)$ & (H) & (I) \\
\hline Australia & 0.518 & 0.869 & 18.9 & 36.4 & 0.0 & 58.3 & 0.041 & No & No \\
\hline Austria & 0.346 & 0.777 & \multicolumn{4}{|c|}{ disjoint } & 0.072 & \multicolumn{2}{|c|}{-} \\
\hline Belarus & 0.231 & 0.295 & \multicolumn{4}{|c|}{ disjoint } & 0.162 & \multicolumn{2}{|c|}{ - } \\
\hline Belgium & 0.666 & 0.985 & 58.4 & 87.6 & 0.0 & 35.7 & 0.022 & Yes & Yes \\
\hline Bulgaria & 0.292 & 1.049 & 0.3 & 1.1 & 11.1 & 0.0 & 0.074 & No & No \\
\hline Canada & 0.439 & 1.044 & 34.0 & 77.4 & 0.0 & 31.2 & 0.016 & Yes & Yes \\
\hline Chile & 0.274 & 0.585 & \multicolumn{4}{|c|}{ disjoint } & 0.074 & \multicolumn{2}{|c|}{ - } \\
\hline Czech Republic & 0.337 & 0.831 & \multicolumn{4}{|c|}{ disjoint } & 0.086 & \multicolumn{2}{|c|}{ - } \\
\hline Denmark & 0.936 & 0.941 & 78.9 & 84.3 & 18.2 & 40.0 & 0.039 & Yes & Yes \\
\hline Estonia & 0.291 & 0.368 & \multicolumn{4}{|c|}{ disjoint } & 0.163 & \multicolumn{2}{|c|}{ - } \\
\hline Finland & 0.285 & 0.574 & 20.9 & 73.4 & 0.0 & 35.7 & 0.210 & No & Yes \\
\hline France & 0.412 & 0.793 & 36.4 & 88.3 & 0.0 & 30.0 & 0.161 & No & Yes \\
\hline E Germany & 0.385 & 0.913 & \multicolumn{4}{|c|}{ disjoint } & 0.077 & \multicolumn{2}{|c|}{ - } \\
\hline W Germany & 0.346 & 0.635 & \multicolumn{4}{|c|}{ disjoint } & 0.067 & & \\
\hline Greece & 0.308 & 0.819 & & & oint & & 0.059 & & \\
\hline Hungary & 0.286 & 0.854 & & & oint & & 0.109 & & \\
\hline Ireland & 0.484 & 0.976 & 12.1 & 25.0 & 8.3 & 27.3 & 0.039 & No & No \\
\hline Iceland & 0.914 & 1.009 & 80.8 & 88.4 & 20.0 & 50.0 & 0.062 & Yes & Yes \\
\hline Israel & 0.568 & 0.613 & & & oint & & 0.043 & & \\
\hline Italy & 0.428 & 0.851 & 39.6 & 92.5 & 0.0 & 10.0 & 0.083 & No & Yes \\
\hline Japan & 0.809 & 0.881 & 19.0 & 23.5 & 0.0 & 37.5 & 0.044 & No & No \\
\hline Latvia & 0.233 & 0.338 & & & oint & & 0.187 & & \\
\hline Lithuania & 0.194 & 0.336 & & & oint & & 0.163 & & \\
\hline Luxemburg & 0.366 & 0.573 & 3.9 & 10.7 & 0.0 & 20.0 & 0.083 & No & No \\
\hline Netherlands & 0.645 & 0.940 & 61.2 & 94.9 & 0.0 & 72.7 & 0.032 & Yes & Yes \\
\hline N.Z. (Maori) & 1.022 & 1.472 & 73.2 & 71.6 & 33.3 & 40.0 & 0.009 & Yes & Yes \\
\hline N.Z. (Non-Maori) & 0.580 & 0.754 & 52.5 & 90.5 & 0.0 & 57.1 & 0.062 & Yes & Yes \\
\hline Norway & 0.804 & 0.905 & 68.8 & 85.5 & 0.0 & 42.9 & 0.042 & Yes & Yes \\
\hline Poland & 0.220 & 0.828 & & & oint & & 0.118 & & \\
\hline Portugal & 0.622 & 0.912 & & & oint & & 0.083 & & \\
\hline Russia & 0.274 & 0.307 & & & oint & & 0.219 & & \\
\hline Slovakia & 0.368 & 1.093 & & & oint & & 0.097 & & \\
\hline Slovenia & 0.322 & 0.404 & & & oint & & 0.108 & & \\
\hline Spain & 0.555 & 0.987 & 42.7 & 77.0 & 0.0 & 9.1 & 0.049 & Yes & Yes \\
\hline Sweden & 0.883 & 0.988 & 83.3 & 94.3 & 0.0 & 50.0 & 0.035 & Yes & Yes \\
\hline Switzerland & 0.632 & 0.890 & 56.8 & 89.8 & 0.0 & 33.3 & 0.066 & Yes & Yes \\
\hline Taiwan & 0.907 & 0.969 & & & oint & & 0.079 & & \\
\hline U.K./England \& Wales & 0.296 & 0.815 & 25.6 & 86.4 & 0.0 & 57.1 & 0.123 & No & Yes \\
\hline U.K./Scotland & 0.748 & 0.959 & 44.1 & 59.0 & 8.3 & 50.0 & 0.042 & Yes & Yes \\
\hline U.K./Northern Ireland & 0.661 & 1.131 & 52.0 & 78.7 & 0.0 & 40.0 & 0.007 & Yes & Yes \\
\hline Ukraine & 0.225 & 0.230 & & & oint & & 0.166 & & \\
\hline United States & 0.332 & 0.896 & & & oint & & 0.061 & & \\
\hline
\end{tabular}


The Iceland data goes back to 1838 , and high variance contributes to the overlap of the hulls. The American data begin in 1933 and show less variance, with thinner hulls. Of the twenty countries with disjoint hulls, (table 2), all have data beginning after the Second World War, except Portugal (1940) and the United States (1933) (table 1). With improvements in nutrition, the advent of antibiotic drugs, and so on, the postwar mortality regime is lower variance (at least in the HMD member countries), which favors disjoint hulls. However, the overlap is not exclusively driven by noisy prewar data. Austria (1947), Bulgaria (1947), Ireland (1950), Japan (1947), Luxembourg (1960), and New Zealand/Maori (1948) are all exclusively postwar data, yet have overlapping hulls. Graphs of the sex-specific hulls for the other forty countries (see table 1) are in Appendix I.

Table 2 gives comparative descriptive statistics of the sex-specific hulls, on a per-country basis. Columns A and B give the area and diameter ratio, respectively, of the female to male hull. The diameter of a convex hull is the greatest pairwise distance between its vertices. ${ }^{5}$ The quantities in columns A and B can take on any value greater than zero. ${ }^{6}$ These are measures of comparable data expanse, in this case, between the sexes, on a same-country basis. For example, Iceland females and males have values in columns A and B close to unity (0.91 and 1.01) while those for the United States are smaller, especially for area $(0.33$ and 0.91$)$. This reflects the situation in figure 4 , in which the hulls for Iceland are much more alike than those for the United States, in which the female is much thinner. Time series data for male mortality typically have higher variance than those for

\footnotetext{
${ }^{5}$ The diameter alternatively refers to the longest line segment between two vertices viz., the line segment itself, not its length. Note that a convex hull may have more than one diameter according to the segment definition, but only one by the length definition. For example, a rectangle has two equal-length diagonals. None of the hulls in this analysis have multiple diameters.

${ }^{6}$ Ignoring pathological cases in which data are perfectly colinear and so have a hull with zero area. There are no such cases in these data. Therefore, throughout, when we discuss hulls, we ignore these cases rather than mention their possible existence.
} 
females. As a result, all the male hulls have larger area than the corresponding female hull, except New Zealand/Maori. Six male hulls have shorter diameters than the corresponding female hull (the value in column B is $>1$ ), but usually males have covered more distance as measured by the diameter. This broadly reflects males' typically lower-mortality starting point, and convergence (in absolute terms) as both sexes experience mortality decline. $^{7}$

Columns $\mathrm{C}$ and $\mathrm{D}$ of table 2 give the intersection area as a percent of male and female hulls. ${ }^{8}$ This statistic varies from 0 to 100 percent; zero values are labeled "disjoint", indicating no path overlap of the mortality relationship over time. The most interesting aspect of these columns is that almost half the hulls (20/42) are disjoint across the sexes, indicating that male mortality decline, as measured by the mortality relationship, does not follow in the footsteps of female mortality decline. Columns E and F give the percentage of points of male and female data (all points, not just hull vertices) contained within their intersection; this statistic varies from 0 to 100. For disjoint hulls, both columns $\mathrm{E}$ and $\mathrm{F}$ are zero by definition. For non-disjoint hulls, the values can still be zero, depending on how the hull vertices are arrayed. A hull contained wholly inside another hull would have a value of $100 \%$ here. ${ }^{9}$ As noted, the male hulls are larger, but there are no male data points in the overlapping region for 16 of the 22 overlapping hulls (i.e., column E is 0.0 for 16 of the non-disjoint hulls). Conversely, only one of the overlapping regions (Bulgaria) is devoid of female data points.

\footnotetext{
${ }^{7}$ For example, if males start at ${ }_{n} q_{x}=0.1$ and females at ${ }_{n} q_{x}=0.05$, and they decline to 0.01 and 0.005 , respectively, the ratio doesn't change but males cover far more distance 0.09 versus 0.045 . See also Sheps (1959).

${ }^{8}$ Another possibility would be the Dice-Sørensen index (Dice, 1945; Sørensen, 1948), which is $2 c /(a+b)$, where $c$ is the overlap area, and $a$ and $b$ are the areas of the two hulls.

${ }^{9}$ Hulls that share an edge but do not otherwise overlap will be disjoint by the criteria of columns $\mathrm{C}$ and $\mathrm{D}$, but not by that of columns $\mathrm{E}$ and F. Edges of two different hulls may touch without overlapping in area, but there are no such examples in the HMD data.
} 
The variance of male time series causes the male hulls to sweep out more area.

The distance between the centroids of each hull is given in column G; these take on any non-negative value. Given that both axes are probabilities, the ceiling in this application is $\sqrt{2}$. The centroid gives the location of the center of mass of the hull, not of all the data points. The male and female hull centroids that are furthest apart are Russia (0.22) and Finland (0.21); these hulls are disjoint and overlapping, respectively. Thus, variance as well as location drives the overlap/non-overlap of the hulls. Indicators for whether the hull centroids lie inside the opposite-sex hull are given in columns H and I. In 13 of the 22 overlapping hulls, the overlap region contains the centroids of both convex hulls.

When mortality is summarized in more than one dimension, a malefemale gap is not the same as a lag. Table 2 shows a diversity of relationships. The male and female mortality hulls are, in many cases, disjoint within the same national population. For some countries, the hulls are quite different from disjoint, and contain each other's centroid. Thinking of the future of male mortality as catching-up to female mortality makes sense on a unidimensional basis, but caution is warranted when ${ }_{5} q_{0}$ and ${ }_{45} q_{15}$ are considered jointly.

\section{ii) Period and cohort}

The Finnish mortality relationship for periods and cohorts is shown in figure 5. Graphs for the ten other countries with cohort data (see table 1) are in Appendix II. The female (red) and male (blue) convex hulls represent the period data for the same years (1878-1924 for Finland) as the cohort data (yellow). The overlap of period and cohort hulls is shaded orange for females (examples in Appendix II), and green for males. The female or male hulls are nested inside white hulls, representing all the available pe- 
riod data (1878-2015 for Finland). The visible white region need not be convex because the red/blue hulls are superimposed.

Consider the data projected onto the horizontal axis (child mortality). Cohort ${ }_{5} q_{0}$ is a combination of ${ }_{1} q_{x}$ for $x=0, \ldots, 4$, in five consecutive years of time. The most important component, ${ }_{1} q_{0}$, is from the same calendar year for both period and cohort data. Thus, the period and cohort spreads along the horizontal axis are very similar. The forty-five year time/age span of ${ }_{45} q_{15}$ brings out more profound differences. For Finnish females, the ranges are similar in length, but overlap little, and the hulls are disjoint. Among the males, the range of cohort ${ }_{45} q_{15}$ data is much smaller than that of the period data, and the cohort hull overlaps the period hull. The minimum $_{45} q_{15}$ data point in the period hull corresponds to 1918 (labeled "A" in the figure), reflecting the influenza pandemic (Ansart et al., 2009) and the Finnish Civil War (Turpeinen, 1979). The 1939-40 Finno-Soviet war did not occur during the time span of the cohort data; its effects can be seen in the white region (labeled " $\mathrm{B}$ ").

As seen in Finnish females and the graphs in Appendix II, the period hull "floats" above the cohort hull. This is the analogue of the gap phenomenon in the time series approach (Goldstein and Wachter 2006). Nevertheless, with the mortality relationship, the story is more complicated than gaps and lags. The overlapping regions are generally small, and five sets of hulls are disjoint, including Finnish females. Considered one dimension at a time, the time series experience gaps and lags. Considered as the mortality relationship, the period hulls do not lag the cohort hulls (viz., do not cover the same ground).

Table 3 gives descriptive statistics for the cohort and period hulls. Apart from column $\mathrm{B}$, all the statistics refer to the period data that are coincident with the cohort data. Column A gives the period to cohort area ratio, which, in the HMD data, is always > 1, except females in Great Britain (analyzed below). This regularity occurs because the range of the ${ }_{45} q_{15}$ is greater for 

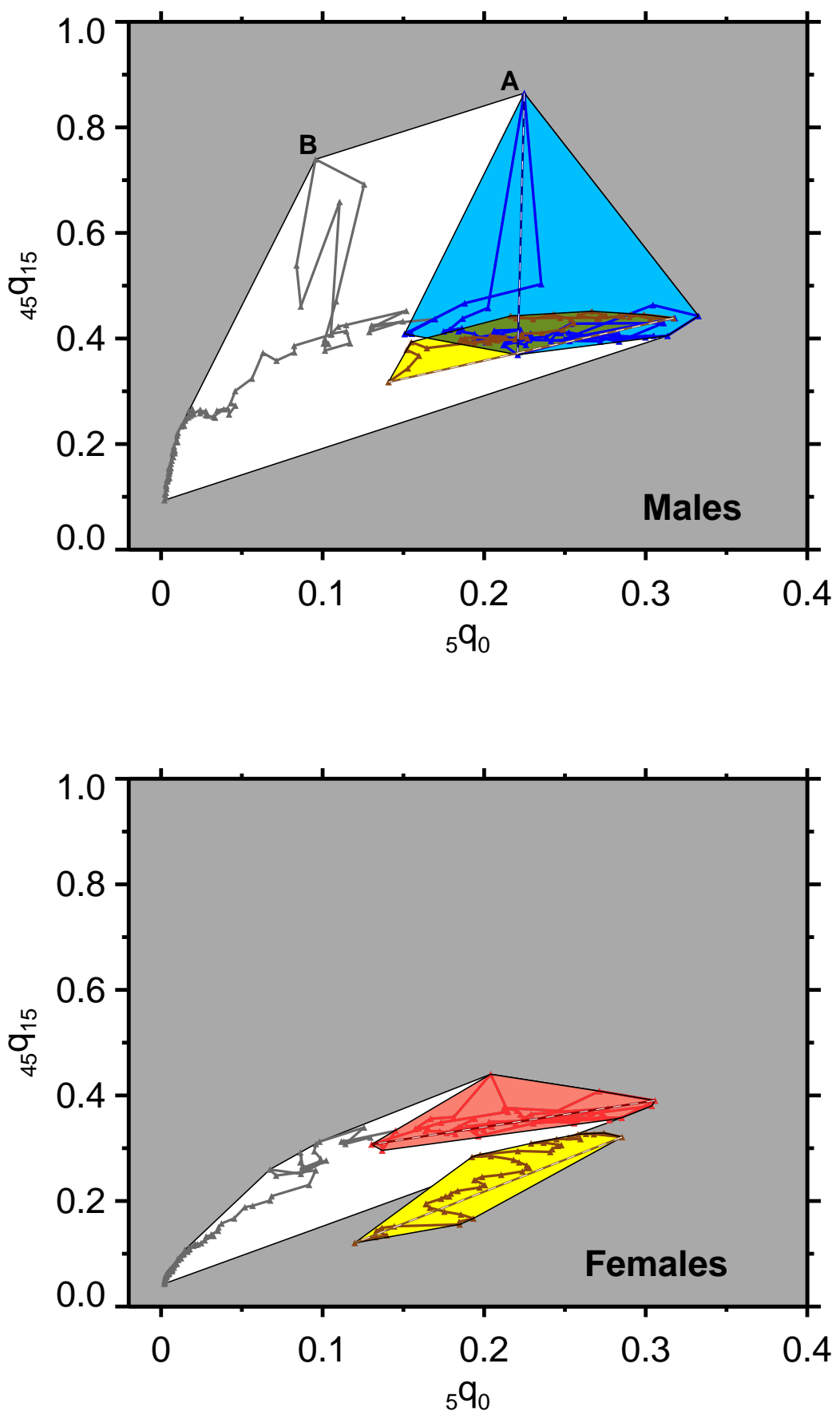

Figure 5: Period and cohort mortality relationship for Finland; data are harmonized so that the period and cohort years coincide. For the period hulls, males are blue and females are red. The cohort mortality relationship is shown in yellow (or green, where it overlaps with male period data). Dashed lines denote the diameters of the hulls. Underplotted in white is the convex hull for the entire extent of the period data; by definition, the red or blue hull is nested in this white hull. The visible white region is therefore not convex, but the union of the white and red/blue regions (ignoring the overlapping yellow hull) is convex. Labels " $\mathrm{A}$ " and " $\mathrm{B}$ " refer to specific events, detailed in the text. 
Table 3: Cohort and period hulls: Descriptive and comparative statistics.

\begin{tabular}{|c|c|c|c|c|c|c|c|c|c|}
\hline \multirow[b]{2}{*}{ Country } & \multirow[b]{2}{*}{ sex } & \multicolumn{2}{|c|}{ period/cohort } & \multicolumn{2}{|c|}{ perimeter/area } & \multirow{2}{*}{$\begin{array}{l}\% \text { of cohort } \\
\text { outside per. }\end{array}$} & \multirow{2}{*}{$\begin{array}{l}-1 \times \text { diametric } \\
\text { corr. of } 2 \text { hulls }\end{array}$} & \multicolumn{2}{|c|}{ canonical corr. } \\
\hline & & area & area* & cohort & period & & & lst & 2nd \\
\hline & & (A) & (B) & $(C)$ & (D) & $(\mathrm{E})$ & $(F)$ & \multicolumn{2}{|c|}{$(G)$} \\
\hline \multirow[t]{2}{*}{ Denmark } & M & 1.525 & 1.157 & 43.09 & 34.41 & disjoint & 0.978 & 0.956 & 0.295 \\
\hline & $\mathrm{F}$ & 1.697 & 1.339 & 54.21 & 33.17 & 95.2 & 0.996 & 0.958 & 0.389 \\
\hline \multirow[t]{2}{*}{ Finland } & M & 5.118 & 4.912 & 52.27 & 24.15 & 32.2 & 0.573 & 0.854 & 0.097 \\
\hline & $\mathrm{F}$ & 1.090 & 1.167 & 51.05 & 40.43 & disjoint & 0.905 & 0.856 & 0.417 \\
\hline \multirow[t]{2}{*}{ France } & M & 3.220 & 2.829 & 29.77 & 15.09 & 36.6 & 0.952 & 0.936 & 0.211 \\
\hline & $\mathrm{F}$ & 1.431 & 1.866 & 46.13 & 33.82 & 90.6 & 0.996 & 0.943 & 0.238 \\
\hline \multirow[t]{2}{*}{ Iceland } & M & 2.235 & 1.407 & 18.14 & 9.33 & 35.3 & 0.999 & 0.887 & 0.110 \\
\hline & $\mathrm{F}$ & 2.524 & 1.498 & 19.14 & 10.01 & 44.6 & 0.987 & 0.874 & 0.076 \\
\hline \multirow[t]{2}{*}{ Italy } & M & 3.635 & 2.288 & 30.32 & 16.34 & 68.7 & 0.654 & 0.949 & 0.331 \\
\hline & $\mathrm{F}$ & 2.272 & 1.544 & 48.38 & 29.87 & disjoint & 0.950 & 0.968 & 0.414 \\
\hline \multirow[t]{2}{*}{ Netherlands } & M & 1.525 & 1.394 & 31.93 & 28.19 & 99.4 & 0.960 & 0.978 & 0.543 \\
\hline & $\mathrm{F}$ & 1.433 & 0.950 & 36.91 & 28.99 & 98.6 & 0.999 & 0.975 & 0.418 \\
\hline \multirow[t]{2}{*}{ Norway } & M & 2.077 & 1.980 & 54.54 & 29.12 & 82.9 & 0.997 & 0.937 & 0.259 \\
\hline & $\mathrm{F}$ & 1.385 & 1.384 & 52.61 & 33.89 & 88.9 & 0.946 & 0.927 & 0.256 \\
\hline \multirow[t]{2}{*}{ Sweden } & M & 3.318 & 2.874 & 35.26 & 15.00 & 35.4 & 1.000 & 0.934 & 0.205 \\
\hline & $\mathrm{F}$ & 3.853 & 3.359 & 45.39 & 16.77 & 40.8 & 0.994 & 0.927 & 0.199 \\
\hline \multirow[t]{2}{*}{ Switzerland } & M & 3.258 & 2.353 & 70.82 & 27.39 & disjoint & 0.997 & 0.987 & 0.128 \\
\hline & $\mathrm{F}$ & 2.319 & 1.689 & 79.52 & 37.50 & disjoint & 1.000 & 0.986 & 0.131 \\
\hline \multirow[t]{2}{*}{ U.K./England \& Wales } & M & 2.550 & 2.188 & 40.73 & 22.52 & 86.6 & 0.890 & 0.970 & 0.035 \\
\hline & $\mathrm{F}$ & 0.776 & 0.614 & 41.63 & 49.33 & 95.3 & 1.000 & 0.970 & 0.344 \\
\hline \multirow[t]{2}{*}{ U.K./Scotland } & M & 1.045 & 1.364 & 54.33 & 51.08 & 90.2 & 0.994 & 0.919 & 0.269 \\
\hline & $\mathrm{F}$ & 0.844 & 0.891 & 55.33 & 51.47 & 92.0 & 0.961 & 0.927 & 0.279 \\
\hline
\end{tabular}


the period data. Column B provides the same statistic, but includes all of the available period data (i.e., including the white region in figure 5), and therefore the period hull encloses many more data points than that of the cohort. To achieve a meaningful statistic, we normalized the area by the number of years; this is not necessary in any other column. As with column A, most of the ratios are $>1$, with females in Great Britain and the Netherlands being exceptions.

As a measure of spread, table 3, columns $\mathrm{C}$ and $\mathrm{D}$ give the perimeter to area ratios for the cohort and period hulls, respectively. ${ }^{10}$ This is notable because only one population (England and Wales, females) has period perimeter-to-area ratio exceeding that for cohort. Larger values in columns $\mathrm{C}$ and $\mathrm{D}$ of table 3 correspond to hulls that are more shard-like in shape, and smaller values to hulls that are more tent-like. Because different hulls (graphs) have different scales, these comparisons work best on a within-country and within-sex basis. Column E gives the percentage of the cohort hull area that lies outside the period hull. Most have some overlap, but five hulls (out of 22) are disjoint, including both sexes for the Swiss data. Finnish males are the most overlapping, with all but $32 \%$ of the cohort hull overlapping with the period hull.

Now we introduce the diametric correlation (column F), or dcor $(\cdot, \cdot)$. The diametric correlation of two hulls, $A, B$, is the cosine of the angle between the diameters of the hulls, and has the sign of the slope of the diameter of $A$ (except, positive if that slope is zero). The diametric correlation is zero if and only if the diameters of the two hulls are perpendicular. Like the

\footnotetext{
${ }^{10}$ The perimeter to area ratio is a positive quantity. As measured by this statistic, a circle has the minimum spread of any convex shape. For a circle, the distance to the furthest point from the center is the radius, $r$, and the perimeter to area ratio is $2 / r$. A square of the same area has a perimeter of $4 \sqrt{\pi} r$, and a perimeter to area ratio of $(2 / r)(2 / \sqrt{\pi})>2 / r$. The distance to the furthest point from the center of the square is $r \sqrt{\pi / 2}>r$. Thus, the square of the same area has more spread and a greater perimeter to area ratio, and so on. The isoperimetric quotient (Apostol and Mnatsakanian, 2004) is a possible alternative to the perimeter to area ratio.
} 
correlation coefficient, $-1 \leq \mathrm{d} \operatorname{cor}(A, B) \leq 1 .^{11}$ The diametric correlation provides a useful dimensionless measure of how parallel, so to say, the two hulls are. Moreover, "correlation is best understood as a measure of angular separation" (Trosset, 2005, p. 2). While diameters may be perfectly parallel - and three of the hulls indeed have perfect diametric correlation (i.e., rounded up to 1.0) - the hulls themselves are polygons which do not have correlations in the traditional sense. The diametric correlation is hull-based, not data-cloud-based. It is a measure of how similar two hulls are oriented, based on the diameters. It resembles a standard (i.e., Pearson) correlation coefficient in that it varies between -1 and 1 , but we stress that it is a measure of orientational agreement of hulls, not (necessarily) the data inside them.

The Finnish example demonstrates the utility of the diametric correlation. For males, the diametric correlation is 0.57 while for females it is 0.91. This is the biggest difference between males and females among all the countries (table 3, column F), as well as the smallest value. When used as a comparative statistic, the diametric correlation quickly points out Finland as a potential outlier. The absolute meaning is the cosine of the angle between the diameters of the Finnish period and cohort hulls. Why not just use the angle itself (i.e., in column F)? This would introduce some practical concerns - degrees or radians, counterclockwise or clockwise, and so on.

Compare these to the hulls illustrated in figure 5, where the alignment of the two hulls seems much better (intuitively) for females. The diametric correlation is more informative than at least one conventional approach:

\footnotetext{
${ }^{11}$ Note that the diametric correlation is only commutative up to absolute value, since $\mathrm{d} \operatorname{cor}(A, B)=\mathrm{d} \operatorname{cor}(B, A)$ in some cases and $\mathrm{d} \operatorname{cor}(A, B)=-\mathrm{d} \operatorname{cor}(B, A)$ in other cases. Since the sign of the diametric correlation is determined only by the slope of the diameter of $A$, the angle between the diameters can be either clockwise or counterclockwise, since $|\cos (\theta)|=|\cos (\pi-\theta)|$. As noted in footnote 5, none of these hulls have multiple diameters. In the case of more than one diameter, define $\operatorname{dcor}(A, B)=\max \{\operatorname{dcor}(A, B)\}$ over all combinations of diameters of $A$ and $B$. In the literature, we have not found any references to the term diametric correlation as it relates to polygons, nor the use of this quantity as we define it.
} 
column G gives the canonical correlations (Hotelling, 1936) of the period and cohort data (not just the hull vertices). ${ }^{12}$ Compared to other countries, Finnish males have the lowest first canonical correlation, although not by far; they have the second-lowest second canonical correlation. While Finnish males stand out in the hull diametric correlations (column F), the differentness according to column $\mathrm{G}$ is more subtle. Compared to conventional approaches, in at least some cases convex hulls can be a quicker or easier route to identify patterns.

Another example is that table 3 (especially columns A and B) points to England and Wales, females, as being different. Figure 6 focuses on the cohort data for England and Wales, females. Consider two subhulls, one from the start of the data to the temporal midpoint, and another from the midpoint +1 to the end of the data. These subhulls are superposed on the hull of the cohort mortality relationship in figure 6 . The subhull for the earlier half of the birth cohorts has horizontal hatching, and that for the later half has vertical hatching. The union of these two subhulls forms a non-convex region which envelops all the cohort data for England and Wales females. The ratio of the area of the hatched region to the area of the convex hull is called the convexity index (Tanimoto, 1987, p. 427); in this example, it is 0.497 . Using the midpoint as the pivot point of the subhulls, this is the lowest such convexity index in the HMD data set among females.

The bottom panel of figure 6 gives a time series plot of ${ }_{45} q_{15}$ and ${ }_{5} q_{0}$; the midpoint (1881) is shown as a vertical rule, and a 19-year period from 1880 has lighter shading. This part of the figure explains (in a mechanical sense) why England and Wales females have the lowest convexity index, and are

\footnotetext{
${ }^{12}$ We used canonical correlations here because we are comparing period and cohort, each of which is, itself, a bivariate mortality relationship. This is a conventional (i.e., in this context, not hull-based) statistical approach. Thus, we analyze canonical correlations of these sets of variates: $\left\{{ }_{5} q_{0}^{p},{ }_{45} q_{15}^{p}\right\}$ and $\left\{{ }_{5} q_{0}^{c},{ }_{45} q_{15}^{c}\right\}$, where the superscripts refer to period and cohort. Pearson correlation would be between two variables, and regression takes one variable on the left hand side. On canonical correlations, see Horst (1961). Canonical correlations were calculated with Stata v.13.1, StatCorp LLC, College Station, Texas.
} 


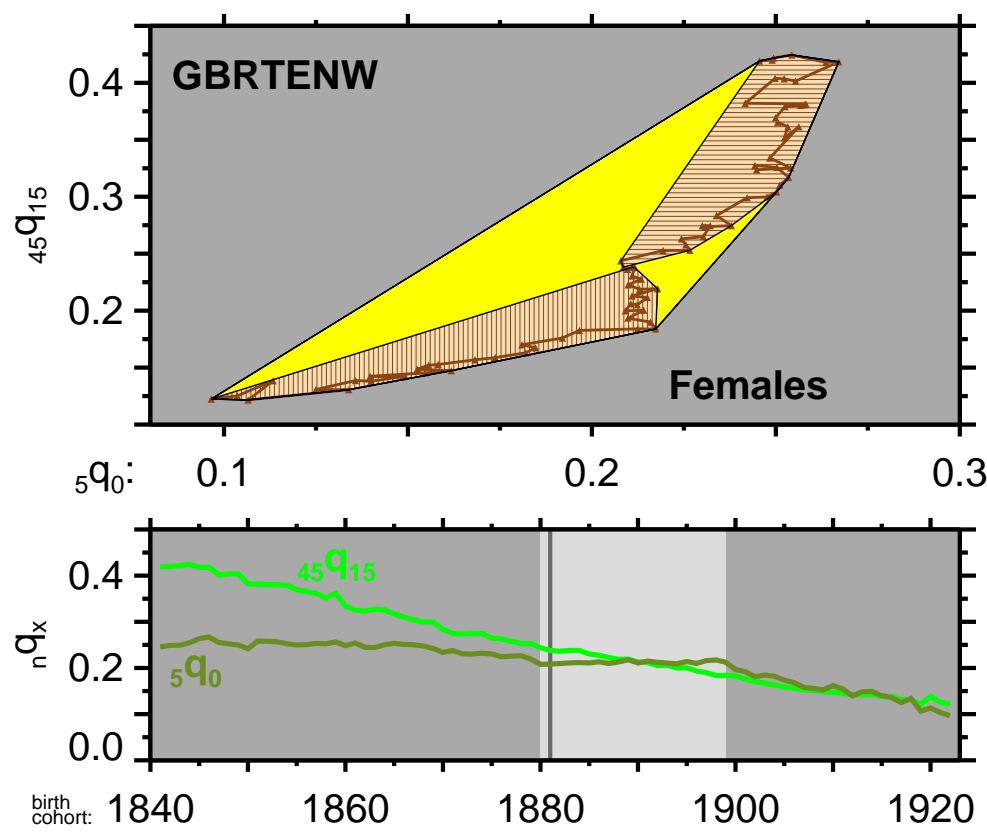

Figure 6: Top panel ("GBRTENW"): cohort mortality hull for England and Wales females, with the sub-hulls for birth cohorts 1841-1881 (horizontal hatching), and 1882-1922 (vertical hatching). Bottom panel: time series plot of ${ }_{5} q_{0}$ (right axis) and ${ }_{45} q_{15}$ (left axis); the axes have different ranges but the same extent, so slopes are comparable. A 19-year period starting in 1880 is a period of stagnation of cohort $5 q_{0}$ 
outliers, in general, in table 3. During the period 1880-99, cohort child mortality stagnates while adult mortality continues to fall. This unusual pattern causes the mortality relationship to rise without much horizontal displacement. This is seen clearly in the later (vertically-hatched) subhull in figure 6. As a result, the cohort convex hull is relatively larger than that of the other hulls, which accounts for the unusual descriptive statistics for England and Wales females in table 3. The convexity index analysis helps bring this into focus. ${ }^{13}$ The usual pattern of improvements along both axes of the mortality relationship is interrupted, creating an outlier. Mortality decline in Victorian England is well-studied, and while trends in ${ }_{5} q_{0}$ have been shown before (Woods et al., 1988), we are unaware of comments on the unusual stagnation of cohort ${ }_{5} q_{0}$ relative to ${ }_{45} q_{15}$, compared to the same relationship in other countries. This is another illustration of the strength of the convex hull approach.

Similar to the analysis of the sex differences, convex hull analysis of periods and cohorts shows that when data are cross-classified as the mortality relationship, period and cohort trends are not well described in terms of gaps and lags. That is not especially surprising - the mortality relationship is not life expectancy and does not have the same dimensionality. Nonetheless, convex hull analysis helps bring out some interesting aspects of the mortality history more efficiently than looking one dimension at a time. What is more, the convex hull approach to the mortality relationship allows quantitative characterizations of the patterns and how they relate to one another. The bottom panel of figure 6 is not hull-based; while such multiple time series graphs can be extremely revealing, it is impossible to calculate quantities such as diametric correlation without using hulls.

\footnotetext{
${ }^{13}$ In this case, the start of the period of ${ }_{5} q_{0}$ stagnation is very close to the midpoint of the cohort series. An elaboration of this approach, not explored here, would be to find the minimum convexity index after trying all possible partitions, of which there are $N-5$, maintaining temporal order. This assumes that the smallest partition will have three points (therefore defining a polygonal hull), and that the first and last three points of the data are non-colinear.
} 
Table 4: Country peeling

\begin{tabular}{|c|c|c|c|c|c|c|}
\hline \multirow{3}{*}{$\begin{array}{l}\text { Peeled } \\
\text { country }\end{array}$} & \multicolumn{2}{|c|}{ Number of points } & \multirow{2}{*}{\multicolumn{2}{|c|}{$\begin{array}{l}\text { Ratio of peeled } \\
\text { to master hull }\end{array}$}} & \multirow{3}{*}{$\begin{array}{l}\text { Number of } \\
\text { countries in } \\
\text { peeled hull }\end{array}$} & \multirow{3}{*}{$\begin{array}{l}\text { Number of } \\
\text { sides in } \\
\text { peeled hull }\end{array}$} \\
\hline & \multirow{2}{*}{$\begin{array}{l}\text { contrib. to } \\
\text { master hull }\end{array}$} & \multirow{2}{*}{$\begin{array}{c}\text { outside } \\
\text { peeled hull }\end{array}$} & & & & \\
\hline & & & area & diameter & & \\
\hline & $(\mathrm{A})$ & (B) & (C) & (D) & $(\mathrm{E})$ & $(\mathbf{F})$ \\
\hline \multicolumn{7}{|l|}{ Males } \\
\hline Belarus & 1 & 5 & 0.9994 & 1.0 & 8 & 12 \\
\hline Estonia & 1 & 2 & 0.9997 & 1.0 & 7 & 11 \\
\hline Finland & 2 & 2 & 0.9736 & 1.0 & 7 & 11 \\
\hline France & 1 & 2 & 0.9919 & 1.0 & 7 & 11 \\
\hline Iceland & 6 & 13 & 0.8092 & 0.9504 & 11 & 15 \\
\hline Russia & 1 & 4 & 0.9977 & 1.0 & 6 & 12 \\
\hline \multicolumn{7}{|l|}{ Females } \\
\hline Belarus & 1 & 3 & 0.9998 & 1.0 & 3 & 12 \\
\hline Iceland & 8 & 16 & 0.6527 & 0.9333 & 10 & 16 \\
\hline N.Z. (Maori) & 4 & 27 & 0.9829 & 1.0 & 3 & 10 \\
\hline
\end{tabular}

\section{iii) Country peeling: Outlier quantification}

In this section, we demonstrate the use of convex hulls for outlier detection when assembling demographic databases such as the HMD. In using convex hulls to identify outliers, we take a country-centered approach, removing one country at a time and seeing how the resulting hull differs from the master hull (i.e., the hull of the entire data set, figure 2). This country peeling differs from Tukey peeling. In figure 2, the female hull is defined by 13 points from three countries and the male hull by 12 points from six countries. Under Tukey peeling, we would remove these 13 or 12 points, respectively, and examine the modified data set, or peel the next hull. With country peeling, we remove entire countries, one at a time, instead of all the vertices of the master convex hull. Country peeling will have no effect except when the country being peeled is one of the countries that contribute points to the master hull. The following analysis demonstrates Iceland as a potential outlier in the HMD data. 

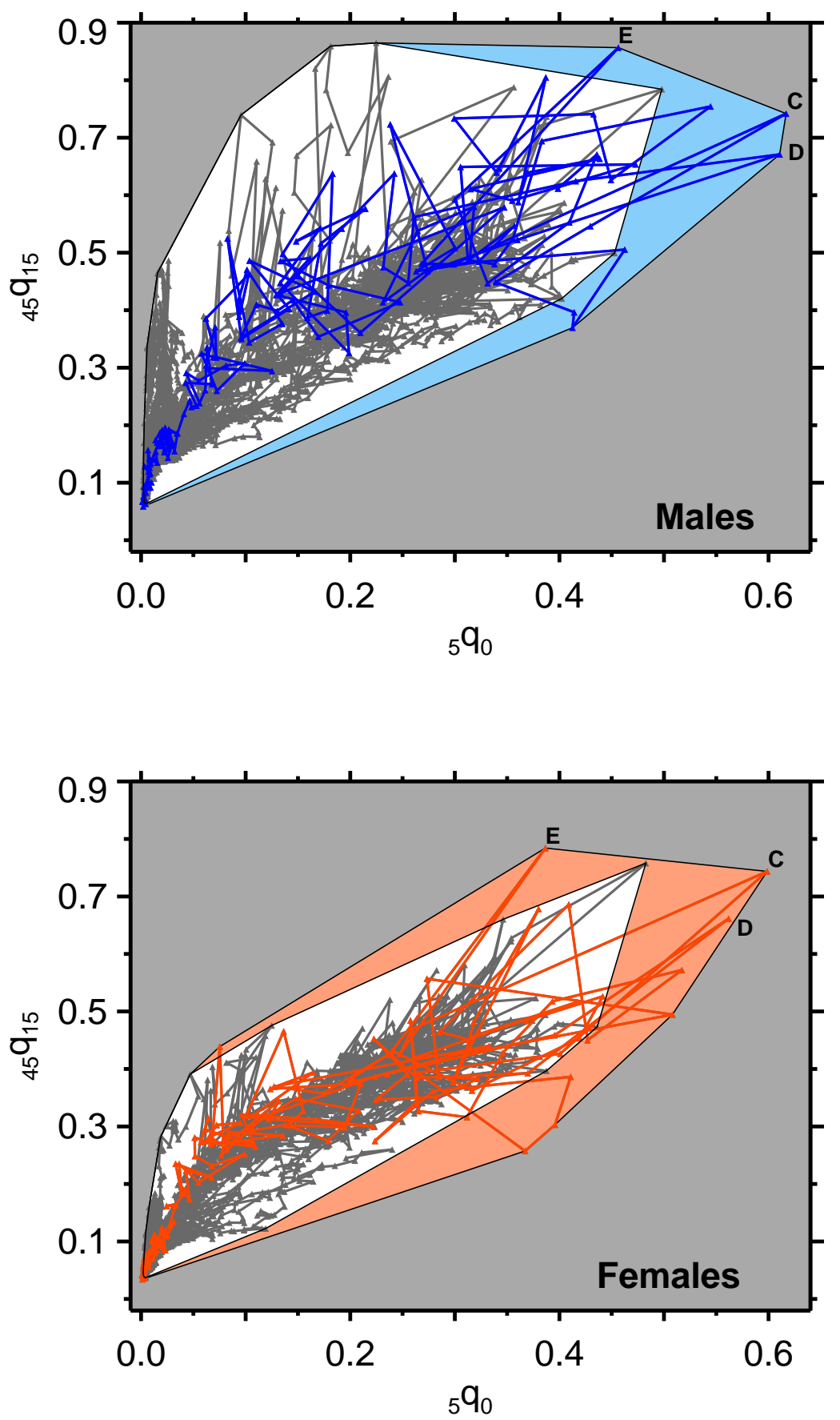

Figure 7: Adult vs child mortality, by sex. For each sex, two hulls are shown: the outer, colored, hull is the master convex hull (the same as shown in figure 2). The inner, white, hull is the result of peeling Iceland, the data of which are shown in color. Labels " $\mathrm{C}$ ", " $\mathrm{D}$ " and " $\mathrm{E}$ " refer to specific events, detailed in the text. 
When a country is peeled, a new, smaller, hull is calculated to reflect the country-peeled data set. Table 4 lists the component countries of the master hull and the number of points each of those countries contributes to the master hull (column A). The next three columns of table 4 give a counterfactual as-if-adding scenario. That is to say, if a country were never in the data set to begin with, and was then added, how much of an outlier would it be relative to the convex hull of the prior mortality relationship. This can be measured by how many points (column B) of the country lie outside the ex ante hull of the as-if-adding thought experiment (i.e., the ex post peeled hull). It can also be measured by how large the peeled hull is, relative to the as-if-added hull (viz., the master hull) (column C). Country peeling for Iceland is shown graphically in figure 7. The inner, peeled, hull (in white, consisting of points from 10 countries for females and 11 for males) is smaller in area and has a smaller diameter than the master hull. Graphs of the seven other peeled hulls (see table 4) are in Appendix III.

Column D gives the diameter of the peeled hull relative to that of the master hull. This column reveals an idiosyncrasy of the HMD data, specifically that Iceland populates the hull at both ends: high mortality for both children and adults (in the 19th century), and low/low mortality (in the 21 st century). The endpoints of the diameter (known as the antipodes) need not be drawn from the same country, but in the HMD data set, they are. Thus, the diameter changes if and only if Iceland is the peeled country (column D). One can visualize this difference in diameters by observing that Iceland's colored hulls extend past the peeled (white) hulls. Column E gives the number of component countries of the peeled hull. For both sexes, the Iceland-peeled hull stands out as having nearly the same number of component countries as the master hull, in contrast to the other peeled countries, where this number declines more. Column $\mathrm{F}$ gives the number of sides of the peeled hull. ${ }^{14}$ This is a measure of the topological complexity of the

\footnotetext{
${ }^{14}$ This is the same as the number of vertices, as long as no edge contains more than two
} 
hull. In all cases except Iceland, the peeled hull has the same number of sides, or fewer, compared to the master hull. The Iceland-peeled hull for both sexes has more sides than the master hull. As with the prior columns, this descriptive statistic identifies Iceland as being qualitatively different.

Country peeling is a technique for outlier detection. It answers the question, "if country $\mathrm{X}$ were being added to the HMD for the first time, how different would it be from the existing countries?" Table 4 shows that most countries are similar in the mortality relationship. Indeed, for females, only three countries would be flagged as outliers if being added (one at a time) to the HMD for the first time. The most severe outlier for both sexes, as quantified by table 4, is Iceland. Iceland is an outlier in large part because it has a long data series (the fourth longest in the HMD, cf. table 1), and it goes from the being worst ${ }_{5} q_{0}$ performer among the small set of HMD polities in the 1830s and 1840s (when it was a colony of Denmark), to, often, the best in the twenty-first century. ${ }^{15}$ Historically, Iceland experienced mortality crises (Schleisner 1851, Tomasson 1977), some of which were associated with the tail end of Europe's "Little Ice Age" (Vasey, 2001), as well as epidemics of infectious disease associated with periodic re-introductions of viruses. Specific years are labeled on figure 7: "C" (1846) and "D" (1882) were measles outbreaks (Cliff et al., 1993; Gunnarsdóttir et al., 2014), while "E" (1843) was an influenza epidemic (Hjaltelin, 1863). These events all correspond to hull vertices for Iceland (and the master hull, figure 2), except for " $\mathrm{D}$ " (1882) for females, in which the point was close to the edge but not a hull vertex. Iceland is now a highly developed country with excellent

vertices. This is unlikely with empirical data, but can arise with gridded data. There are no such instances in any data analyzed here.

${ }^{15}$ Iceland is also small (f.e., total population under 100,000 in 1900), which enhances the variability of the annual life tables. To address this, the analysis of this section was replicated using life tables from five years (of time). Results are presented in Appendix IV. Iceland is still the principal outlier, for both sexes. The master and peeled hulls are smaller, because 5-year life tables are buffered against shock events like epidemics. The overall character of the analysis is the same, although some of the particulars change. 
health statistics. Most countries are not outliers, reflecting commonalities in the mortality relationship in the HMD data. The take home message is that convex hulls are an effective tool for qualitatively identifying outliers, as well as quantifying their degree of outlierness.

When adding new countries to an existing database, different mortality patterns are sometimes flagged for potential recalculation, taking into account adjustments for completeness of registration, age misreporting, and so on (f.e., Rosenwaike and Preston 1984, Preston et al. 1999, Hill et al. 2005, Hill et al. 2009, Palloni et al. 2016). Recall that, considering both sexes, nine of the HMD populations would be considered outliers (to some extent) if added to the database for the first time. While convex hull analysis by itself cannot replace human judgment, it can provide a useful way to quantify the degree of difference between the added population(s) and the existing pattern.

We conclude this section with an example of using convex hulls to assess the differentness of various data sets (figure 8 ). Here we illustrate the mortality relationship for the Latin American Mortality Database (2016) in comparison to the HMD. ${ }^{16}$ This is relevant because it has been postulated that Latin America has a characteristic mortality pattern (Arriaga, 1968; Arriaga and Davis, 1969; Palloni, 1981; Palloni and Wyrick, 1981; United Nations, 1982; Palloni et al., 2006; Palloni and Pinto-Aguirre, 2011; Palloni and Souza, 2013; Palloni et al., 2015). The HMD hulls, which are larger, are shown in white, and the Latin American Mortality Database (Lambda) hulls are superposed. The earliest Lambda life tables date from 1908. Thus, to make a fairer comparison, we also show (as a dashed outline) the HMD hull for all data since 1900 .

A complete exploration of Latin America/HMD comparisons using the convex hull approach is beyond the present scope. However, figure 8 shows

\footnotetext{
${ }^{16}$ The Lambda countries are: Argentina, Brazil, Chile, Colombia, Costa Rica, Cuba, Dominican Republic, Ecuador, El Salvador, Guatemala, Honduras, Mexico, Nicaragua, Panama, Paraguay, Peru, Uruguay, Venezuela.
} 

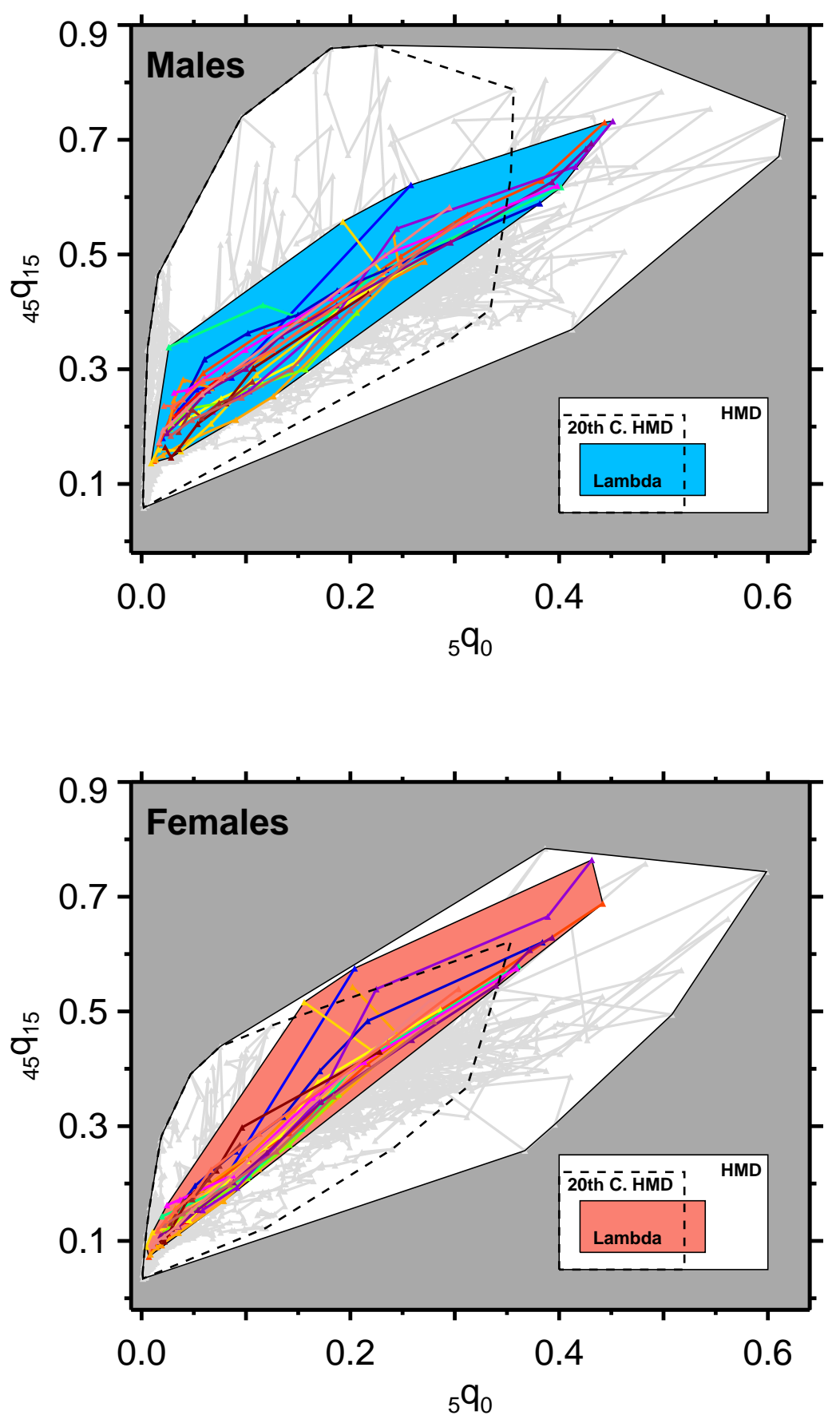

Figure 8: Comparison of HMD and Lambda databases. HMD hulls are shown in white, and hulls of HMD data since 1900 ("20th C.") are shown as dashed lines. The Lambda hulls are color-shaded. 
that the Latin American mortality relationship - based on the Lambda data - is not completely different from that of the HMD. Specifically, the Lambda hulls are subsets of the overall HMD hulls. From this, we can say that there are not wholesale differences between life tables of these two data sets. An important caveat is that the mortality relationship, as defined, is only one way to look at the life table. Also, this is a comparison of Lambda and the HMD, not of Latin American and rest-of-the-world mortality; it is limited by sample selection. Note also that the Lambda hulls do exceed the HMD hulls constructed from data since 1900. This makes sense, given the typical associations between life table measures and economic development (f.e., Preston, 1975), and that the HMD is more skewed toward industrialized countries.

\section{Conclusion}

The goal of this work is to introduce convex hulls to demography, as tools for exploratory data analysis (in the sense of Tukey, 1977). We make the case for the use of convex hulls as the best way, in some cases, to discern certain patterns in demographic data, such as identifying outliers. Additionally, we present a diversity of descriptive statistics that can be applied to comparative convex hull analysis, including point-, area-, and diameterbased measures. We also introduce a correlation measure based on hull diameters. One of the themes of Gnanadesikan's fine textbook (1997) on multivariate methods is that more often than not, there are multiple ways to get the same substantive answer. We believe that, sometimes, the path from point A to point B is shorter when convex hulls are used.

Convex hulls can bring certain patterns into sharp relief when they might otherwise hide in the data. A number of the findings brought out by the convex hulls approach — for example female cohort mortality patterns in Victorian England and Wales, or Iceland's move from worst to first - 
are more clearly and quickly seen with convex hulls than with other techniques. Verification of these patterns using more time-tested techniques (f.e., the bottom panel of figure 6) does not seem to us to be a weakness of the convex hull approach. What is more, convex hulls provide a framework for generalizing gaps and lags to multiple dimensions, not always with the same conclusions as the univariate case.

Another strength of the convex hull approach is the number of different descriptive statistics they generate, as demonstrated in the tables. These statistics are influenced by the extremes of the data, not the central tendencies - which may or may not be an asset, depending upon the application. For example, the diametric correlation more readily identified Finnish males as an outlier in the period:cohort analysis, compared to canonical correlations. In cases where outlying observations dominate, and cause peculiar difficulties for convex hull analysis, the data may be (appropriately enough) Tukey peeled one or more times.

Traditional approaches to data analysis, using conditional means, are very well explored. Working with data clouds considered as clouds are what convex hulls have to offer. Not as a replacement of conditional mean-based approaches, but as a complement. This is the first work of which we are aware that makes extensive use of convex hulls as an analytic tool or framework for population data. We hope our analysis demonstrates convex hull analysis as a promising tool for demographers. We encourage population scientists to consider their use. Certain modifications, such as stratifying the country-peeling approach by time period, are also worth considering but are beyond the present scope, which is designed to introduce the hull approach to population studies. Another extension would be to study the mortality relationship under the logit (Brass and Coale, 1968) or $\log (-\log (\cdot)$ ) (Llewelyn 1968, Thatcher 1990) transformations (see footnote 4 on transformations). Yet another approach could be to look at first-differences in the time series of the mortality relationship. 
One of the strengths of our approach is that we use convex hulls as a descriptive tool, and as such there are no assumptions that can be violated. As with all analytic tools, convex hulls have some potential limitations. Convex hulls are only as good as the data used to construct them; they are not a guarantee to detect defective data. Convex hulls are determined by extreme values. As such, convex hulls should prove to be quite useful in the identification of defective data; outliers become readily apparent. Country peeling is a technique introduced here to identify outliers in ensemble life table databases. However, they can only be used to identify outliers in certain senses: some points that are classified as outliers by some other measures, such as Gower distance (Gower, 1966), may lie inside the convex hull of the data.

Convex hulls compliment standard approaches, and we do not propose them as a replacement for anything. The usefulness of convex hulls in population studies is not limited to the mortality relationship. Application to the demographic transition (Kirk, 1996) seems especially promising. Historical demography is another area in which convex hulls could be applied profitably, with "log(GRR) plots" - i.e., graphs with $\log (\mathrm{GRR})$ on the $y$ axis and $\log (\mathrm{e}(0))$ on the $x$-axis (Wachter, 2014, p. 133) - particularly inviting.

\section{Acknowledgments}

We thank the Ministry of Science and Technology, Republic of China, for financial support under grant number MOST 104-2912-1-305-508. We thank Michael Galloy for advice with the IDL triangulate routine, and Mati Meron for help with his library of IDL routines. The idea for this work was inspired by stimulating discussions at the HMD/LAMB $\delta$ A meeting in Berkeley, California, July 2015. We thank the Quetelet Journal anonymous peer reviewers for thoughtful comments. We thank Andrew J. Lew for comments on a draft. We received useful feedback from seminar audiences at the UC Irvine Department of Economics and the Max Planck Institute for Demographic Research, and from audiences at the 2017 NBER Cohort Studies 
meeting and the IUSSP workshop on "Mortality: Past, present and future". We thank also Philip Stark, Tim Riffe, Alberto Palloni, and Hiram BeltránSánchez. Especial thanks to Amar A. Hamoudi for detailed and thoughtful feedback.

\section{Works Cited}

Aldous, David J., Bert Fristedt, Philip S. Griffin, and William E. Pruitt. 1991. "The number of extreme points in the convex hull of a random sample." Journal of Applied Probability 28(2):287-304. DOI: $10.2307 / 3214867$.

Ansart, Séverine, Camille Pelat, Pierre-Yves Boelle, Fabrice Carrat, Antoine Flahault, and Alain-Jacques Valleron. 2009. “Mortality burden of the 1918-1919 influenza pandemic in Europe." Influenza and Other Respiratory Viruses 3(3):99-106. DOI: 10. 1111/j.1750-2659.2009.00080.x.

Apostol, Tom M. and Mamikon A. Mnatsakanian. 2004. "Isoperimetric and isoparametric problems." American Mathematical Monthly 111(2):118-136. DOI: 10.1080/00029890.2004.11920056.

Arriaga, Eduardo E. 1968. New life tables for Latin American populations in the nineteenth and twentieth centuries. No. 3 in Population Monographs, Institute of International Studies, University of California, Berkeley.

Arriaga, Eduardo E. and Kingsley Davis. 1969. "The pattern of mortality change in Latin America." Demography 6(3):223242. DOI: $10.2307 / 2060393$.

Barbieri, Magali, John R. Wilmoth, Vladimir M Shkolnikov, Dana Glei, Domantas Jasilionis, Dmitri Jdanov, Carl Boe, Timothy Riffe, Pavel Grigoriev, and Celeste Winant. 2015. “Data resource profile: The Human Mortality Database (HMD)." International Journal of Epidemiology 44(5):1549-1556. DOI: 10.1093/ije/dyv105.

Barnett, V. 1976. "The ordering of multivariate data." Journal of the Royal Statistical Society, Series A 139(3):318-355. DOI: $10.2307 / 2344839$.

Bebbington, A. C. 1978. "A method of bivariate trimming for robust estimation of the correlation coefficient." Applied Statistics 27(3):221-226. DOI: 10.2307/2347156.

Bhattacharya, Jay, Christina Gathmann, and Grant Miller. 2013. "The Gorbachev anti-alcohol campaign and Russia's mortality crisis." American Economic Journal: Applied Economics 5(2):232-260. DOI: 10. 1257 /app.5.2.232.

Blackwell, Paul. 1992. "Convex hulls of selected subsets of a Poisson process." Journal of Applied Probability 29(4):814-824. DOI: $10.2307 / 3214714$.

Brass, William and Ansley J. Coale. 1968. "Methods of analysis and estimation." In William Brass, Ansley J. Coale, Paul Demeney, Don F. Heisel, Frank Lorimer, Anatole Romaniuk, and Etienne Van de Walle (eds.), The demography of tropical Africa, chap. 3, pp. 88-139. Princeton University Press, Princeton.

Cliff, Andrew, Peter Haggett, and Matthew Smallman-Raynor. 1993. Measles: An historical geography of a major human viral dis- 
ease, from global expansion to local retreat, 1840-1990. Blackwell, Oxford.

Coale, Ansley J. and Paul Demeny. 1983. Regional model life tables and stable populations. Academic Press, San Diego, second ed. DOI: 10.1016/C2013-0-07295-7.

Cornwell, William K., Dylan W. Schwilk, and David D. Ackerly. 2006. "A traitbased test for habitat filtering: Convex hull volume." Ecology 87(6):1465-1471. DOI: $10.1890 / 0012-9658(2006) 87$ [1465: ATTFHF]2.0.CO;2.

de Berg, Mark, Otfried Cheong, Marc van Kreveld, and Mark Overmars. 2008. Computational geometry: Algorithms and applications. Springer, Berlin, third ed. DOI: 10.1007/978-3-540-77974-2.

DeGroot, Morris H. and Mark J. Schervish. 2002. Probability and statistics. AddisonWesley, Reading, Massachusetts, third ed.

Demeny, Paul and Paul Gingrich. 1967. “A reconsideration of Negro-white mortality differentials in the United States." Demography 4(2):820-837. DOI: 10.2307/ 2060320.

Dice, Lee R. 1945. "Measures of the amount of ecologic association between species." Ecology 26(3):297-302. DOI: $10.2307 /$ 1932409.

Eddy, William F. 1980. "The distribution of the convex hull of a Gaussian sample." Journal of Applied Probability 17(3):686695. DOI: $10.2307 / 3212962$.

Efron, Bradley. 1965. "The convex hull of a random set of points." Biometrika 52(3/4):331-343. DOI: $10.2307 / 2333687$.
Galloway, Patrick R. 1994. “A reconstruction of the population of North Italy from 1650 to 1881 using annual inverse projection with comparisons to England, France, and Sweden." European Journal of Population 10(3):223-274. DOI: 10.1007/ BF01265303.

Georgakis, Giannis and George Tziafetas. 1982. "Stochastic projection of the population distribution in Greece." European Demographic Information Bulletin 13(3):120-134. DOI: 10.1007/ BF02917606.

Gerland, Patrick. 2014. “UN Population Division's methodology in preparing base population for projections: Case study for India." Asian Population Studies 10(3):274-303. DOI: 10.1080/17441730. 2014.947059 .

Getz, Wayne M. and Christopher C. Wilmers. 2004. "A local nearestneighbor convex-hull construction of home ranges and utilization distributions." Ecography 27(4):489-505. DOI: $10.1111 / j .0906-7590.2004 .03835 . x$.

Gnanadesikan, Ramanathan. 1997. Methods for statistical data analysis of multivariate observations. Wiley, New York, second ed. DOI: $10.1002 / 9781118032671$.

Goldstein, Joshua R. and Kenneth W. Wachter. 2006. "Relationships between period and cohort life expectancy: Gaps and lags." Population Studies 60(3):257269. DOI: $10.1080 / 00324720600895876$.

Goldstone, J. A. 1986. "The demographic revolution in England: A reexamination." Population Studies 40(1):533. DOI: $10.1080 / 0032472031000141816$.

Gower, J. C. 1966. "Some distance properties of latent root and vector methods 
used in multivariate analysis." Biometrika 53(3/4):325-338.

Gunnarsdóttir, Sandra, Haraldur Briem, and Magnús Gottfređsson. 2014. “Umfang og áhrif mislingafaraldranna 1846 og 1882 á Íslandi." Lxknabladið 100(4):211-216.

Hill, Kenneth, Yoonjoung Choi, and Ian Timæus. 2005. "Unconventional approaches to mortality estimation." Demographic Research S4(12):281-300. DOI: 10.4054/DemRes.2005.13.12.

Hill, Kenneth, Danzhen You, and Yoonjoung Choi. 2009. "Death distribution methods for estimating adult mortality: Sensitivity analysis with simulated data errors." Demographic Research 21(9):235-254. DOI: 10.4054/DemRes.2009.21.9.

Hjaltelin, John. 1863. "Influenza epidemics in Iceland." British Medical Journal 1(118):357-358. DOI: 10.1136/bmj . 1.118 .353 .

Hodge, Victoria and Jim Austin. 2004. "A survey of outlier detection methodologies." Artificial Intelligence Review 22(2):85-126. DOI: 10.1023/B:AIRE. 0000045502.10941 .a9.

Horst, Paul. 1961. "Relations among $m$ sets of measures." Psychometrika 26(2):129149. DOI: $10.1007 /$ BF02289710.

Hotelling, Harold. 1936. "Relations between two sets of variates." Biometrika 28(3/4):321-377. DOI: 10.2307/2333955.

Huber, Peter J. 1972. "Robust statistics: A review." Annals of Mathematical Statistics 43(4):1041-1067. DOI: 10.1214/aoms/ 1177692459 .
Hueter, Irene. 1994. "The convex hull of a normal sample." Advances in Applied Probability 26(4):855-875. DOI: $10.2307 /$ 1427894.

Human Mortality Database. 2017. http:// www.mortality.org/. Accessed 16 March 2017.

Kemeny, John G. and J. Laurie Snell. 1962. Mathematical models in the social sciences. MIT Press, Cambridge, Massachusetts.

Kemeny, John G., J. Laurie Snell, and Gerald L. Thompson. 1966. Introduction to finite mathematics. Prentice-Hall, Englewood Cliffs, New Jersey, second ed.

Kirk, Dudley. $1996 . \quad$ "Demographic transition theory." Population Studies 50(3):361-387. DOI: $10.1080 / 0032472031000149536$.

Latin American Mortality Database. 2016. https://www.ssc.wisc.edu/cdha/ latinmortality/. Accessed 19 December 2017.

Llewelyn, F. W. M. 1968. "The $\log (-\log )$ transformation in the analysis of fruit retention records." Biometrics 24(3):627638. DOI: $10.2307 / 2528322$.

Massé, Bruno. 2000. "On the LLN for the number of vertices of a random convex hull." Advances in Applied Probability 32(3):675-681. DOI: 10.1239/aap/ 1013540238.

Mosteller, Frederick and John W. Tukey. 1977. Data analysis and regression: A second course in statistics. Addison-Wesley, Reading, Massachusetts.

Murray, C. J. L., B. D. Ferguson, A. D. Lopez, M. Guillot, J. A. Salomon, and O. Ahmad. 2003. "Modified logit life 
table system: Principles, empirical validation, and application." Population Studies 57(2):165-182. DOI: 10.1080/ 0032472032000097083.

Palloni, Alberto. 1981. "Mortality in Latin America: Emerging patterns." Population and Development Review 7(4):623-649. DOI: $10.2307 / 1972801$.

Palloni, Alberto, Mary McEniry, Rebeca Wong, and Martha Peláez. 2006. "The tide to come: Elderly health in Latin America and the Caribbean." Journal of Aging and Health 18(2):180-206. DOI: $10.1177 / 0898264305285664$.

Palloni, Alberto, Guido Pinto, and Hiram Beltrán-Sánchez. 2015. "Estimation of life tables 1850-2010: Adjustments for relative completeness and age misreporting." In Two centuries of mortality decline in Latin America: From hunger to longevity, chap. 2, pp. 97-117. mimeo., https://www.ssc.wisc.edu/cdha/ latinmortal ity/wp-content/uploads/ book_Ch2.pdf.

- 2016. "Estimation of life tables in the Latin American Data Base (LAMBdA): Adjustments for relative completeness and age misreporting." Unpublished report: http://www.un. org/en/development/desa/population/ events/pdf/expert/26/notes/Pal loni_ 2016_Est-of- 1 i fe-in-LAMBdA.pdf.

Palloni, Alberto and Guido Pinto-Aguirre. 2011. "Adult mortality in Latin America and the Caribbean." In Rogers and Crimmins (2011), chap. 5, pp. 101-132. DOI: 10.1007/978-90-481-9996-9_5.

Palloni, Alberto and Laetícia Souza. 2013. "The fragility of the future and the tug of the past: Longevity in Latin America and the Caribbean." Demographic Research 29(21):543-578. DOI: 10.4054/DemRes. 2013.29.21.

Palloni, Alberto and Randy Wyrick. 1981. "Mortality decline in Latin America: Changes in the structure of causes of deaths, 1950-1975." Social Biology 28(34):187-216. DOI: $10.1080 / 19485565$. 1981.9988458.

Pampel, Fred C. 2002. "Cigarette use and the narrowing sex differential in mortality." Population and Development Review 28(1):77-104. DOI: $10.1111 / \mathrm{j}$. 1728-4457.2002.00077.x.

Preparata, Franco P. and Michael Ian Shamos. 1985. Computational geometry: An introduction. Springer, New York. DOI: 10.1007/978-1-4612-1098-6.

Preston, Samuel H. 1975. "The changing relation between mortality and level of economic development." Population Studies 29(2):231-248. DOI: 10.1080/00324728. 1975.10410201.

Preston, Samuel H., Irma T. Elo, and Quincy Stewart. 1999. "Effects of age misreporting on mortality estimates at older ages." Population Studies 53(2):165-177. DOI: $10.1080 / 00324720308075$.

Rao, Chalapati, Alan D. Lopez, Gonghuan Yang, Stephen Begg, and Jiemin Ma. 2005. "Evaluating national cause-ofdeath statistics: Principles and application to the case of China." Bulletin of the World Health Organization 83(8):618-625.

Reniers, Georges, Bruno Masquelier, and Patrick Gerland. 2011. "Adult mortality in Africa." In Rogers and Crimmins (2011), chap. 7, pp. 151-170. DOI: 10 . 1007/978-90-481-9996-9_7. 
Rogers, Richard G. and Eileen M. Crimmins (eds.). 2011. International handbook of adult mortality. Springer, Dordrecht, Netherlands. DOI: 10.1007/ 978-90-481-9996-9.

Rosenwaike, Ira and Samuel H. Preston. 1984. "Age overstatement and Puerto Rican longevity." Human Biology 56(3):503525 .

Schleisner, P. A. 1851. "Vital statistics of Iceland." Journal of the Statistical Society of London 14(1):1-10. DOI: 10.2307/2338109.

Sheps, Mindel C. 1959. “An examination of some methods of comparing several rates or proportions." Biometrics 15(1):87-97. DOI: $10.2307 / 2527603$.

Snedecor, George W. and William G. Cochran. 1989. Statistical methods. Iowa State University Press, Ames, eighth ed.

Snyder, Timothy Law and J. Michael Steele. 1993. "Convex hulls of random walks." Proceedings of the American Mathematical Society 117(4):1165-1173. DOI: 10.2307/ 2159548.

Sørensen, Thorvald J. 1948. "A method of establishing groups of equal amplitude in plant sociology based on similarity of species content and its application to analyses of the vegetation on Danish commons." Biologiske Skrifter, Kongelige Danske Videnskabernes Selskab 5:1-34.

Suri, Subhash, Kevin Verbeek, and Hakan Yıldız. 2013. "On the most likely convex hull of uncertain points." In Hans L. Bodlaender and Giuseppe F. Italiano (eds.), Algorithms - ESA 2013: 21st annual European symposium, Sophia Antipolis, France, September 2-4, 2013. Proceedings, pp. 791802. No. 8125 in Lecture Notes in Computer Science, Springer, Berlin. DOI: 10 . 1007/978-3-642-40450-4_67.
Tanimoto, Steven L. 1987. The elements of artifical intelligence: An introduction using LISP. Computer Science Press, Rockville, Maryland.

Thatcher, A. R. 1990. "Some results on the Gompertz and Heligman and Pollard laws of mortality." Journal of the Institute of Actuaries 117(1):135-149. DOI: 10.1017/ S0020268100043043.

Timæus, Ian M. and Tom A. Moultrie. 2013. "Fitting model life tables to a pair of estimates of childhood and adult mortality." In Tom Moultrie, Rob Dorrington, Allan Hill, Kenneth Hill, Ian Timæus, and Basia Zaba (eds.), Tools for demographic estimation, chap. 32, pp. 348-356. International Union for the Scientific Study of Population, Paris.

Tomasson, Richard F. 1977. "A millennium of misery: The demography of the Icelanders." Population Studies 31(3):405-427. DOI: 10.1080/00324728. 1977.10412758 .

Trosset, Michael W. 2005. "Visualizing correlation." Journal of Computational and Graphical Statistics 14(1):1-19. DOI: 10 . 1198/106186005X27004.

Tukey, John W. 1962. "The future of data analysis." Annals of Mathematical Statistics 33(1):1-67. DOI: 10.1214/aoms/ 1177704711.

1975. "Mathematics and the picturing of data." In Ralph D. James (ed.), Proceedings of the International Congress of Mathematicians, Vancouver 1974, vol. 2, pp. 523531.

Exploratory data analy sis. Addison-Wesley, Reading, Massachusetts. 
Turpeinen, Oiva. 1979. "Fertility and mortality in Finland since 1750." Population Studies 33(1):101-1 14. DOI: 10.1080/ 00324728.1979 .10412779 .

United Nations. 1982. Model life tables for developing countries. No. 77 in Population Studies, United Nations Department of International Economic and Social Affairs, New York.

Vasey, Daniel E. 2001. "A quantitative assessment of buffers among temperature variations, livestock, and the human population of Iceland, 1784 to 1900." Climatic Change 48(1):243-263. DOI: 10.1023/A: 1005686015776.

Wachter, Kenneth W. 2014. Essential demographic methods. Harvard University Press, Cambridge.

Wilmoth, John, Sarah Zureick, Vladimir Canudas-Romo, Mie Inoue, and Cheryl Sawyer. 2012. "A flexible two-dimensional mortality model for use in indirect estimation." Pop- ulation Studies 66(1):1-28. DOI: $10.1080 / 00324728.2011 .611411$.

Woods, R. I., P. A. Watterson, and J. H. Woodward. 1988. "The causes of rapid infant mortality decline in England and Wales, 1861-1921. Part I." Population Studies 42(3):343-366. DOI: 10.1080/ 0032472031000143516 .

Woods, Robert. 1993. “On the historical relationship between infant and adult mortality." Population Studies 47(2):195-219. DOI: $10.1080 / 0032472031000146976$.

2000. The demography of Victorian England and Wales. Cambridge University Press, Cambridge.

Woods, Robert and P. R. Andrew Hinde. 1987. "Mortality in Victorian England: Models and patterns." Journal of Interdisciplinary History 18(1):27-54. DOI: 10 . $2307 / 204727$.

Wrigley, E. A. and R. S. Schofield. 1981. The population history of England, 1541-1871: A reconstruction. Edward Arnold, London. 


\section{Appendix I: Sex-specific hulls for all countries}

This appendix shows the male and female sex-specific hulls, except for Iceland and the United States, which are shown in figure 4.

Australia

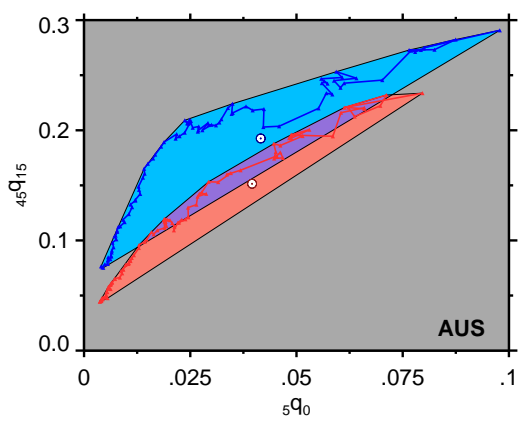

Belgium

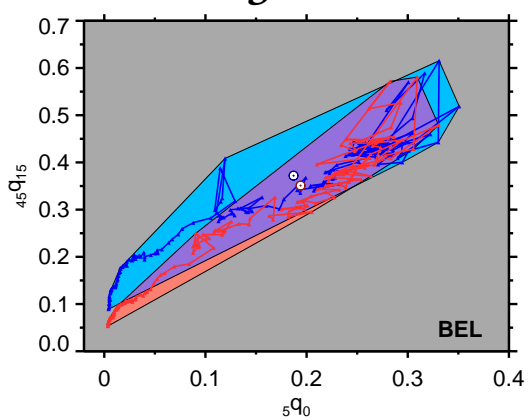

Belarus

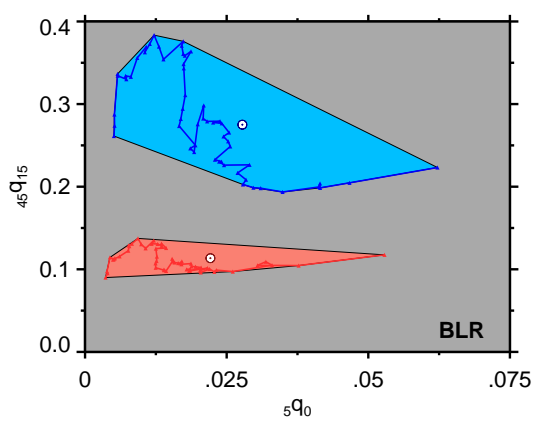

Switzerland

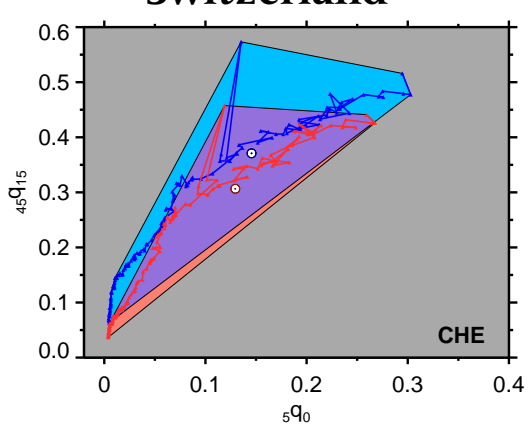

Austria
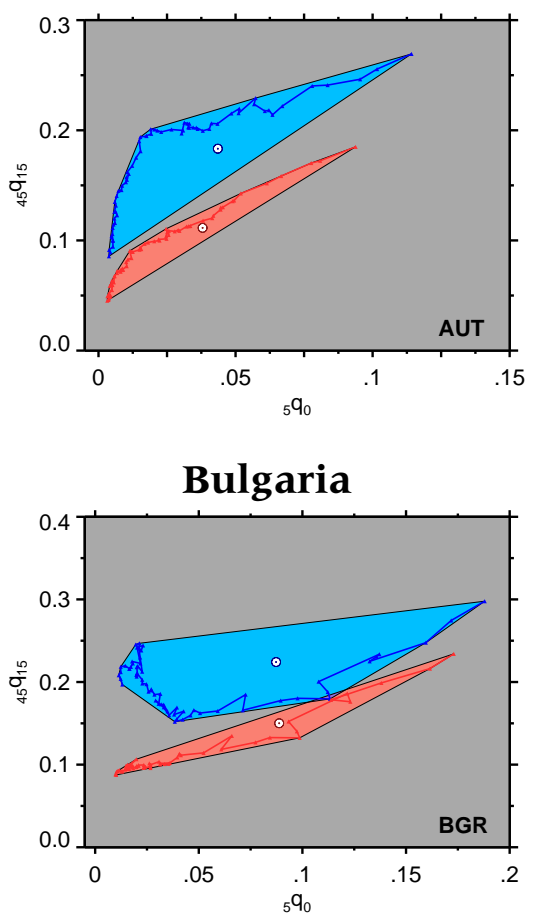

Canada

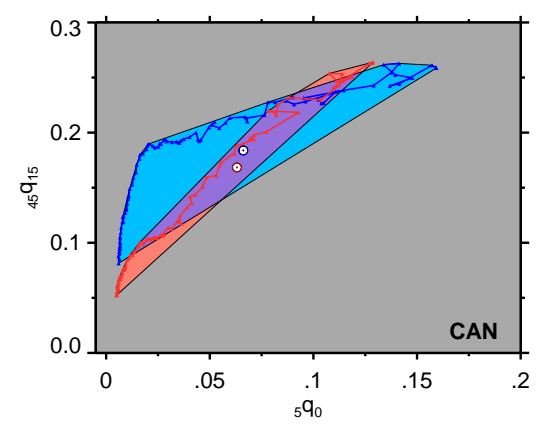

Chile

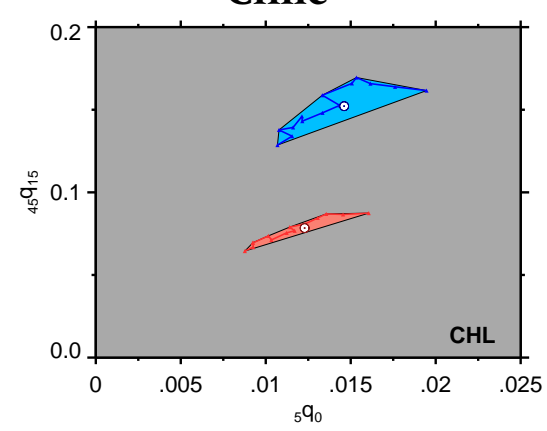



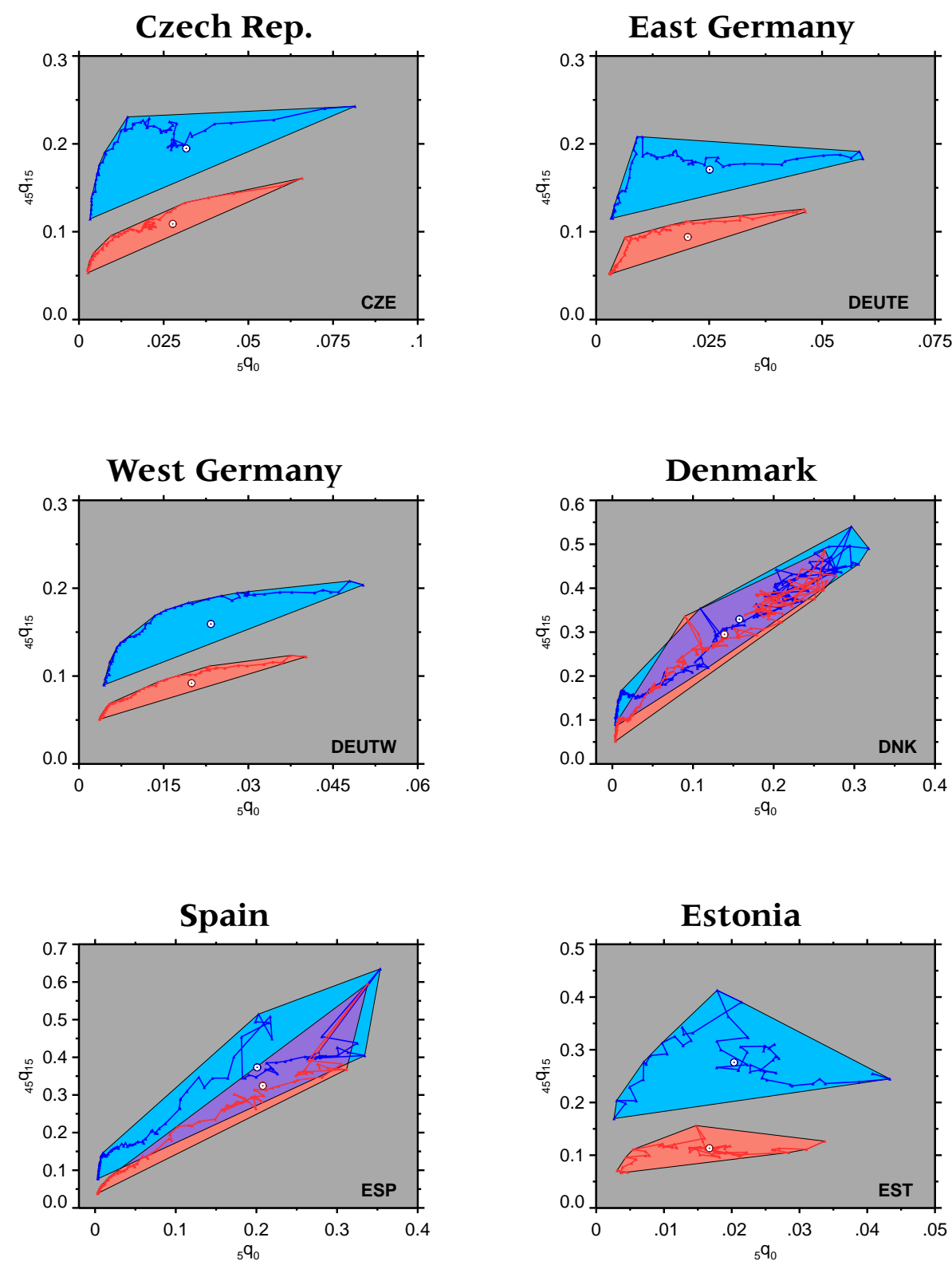

Finland

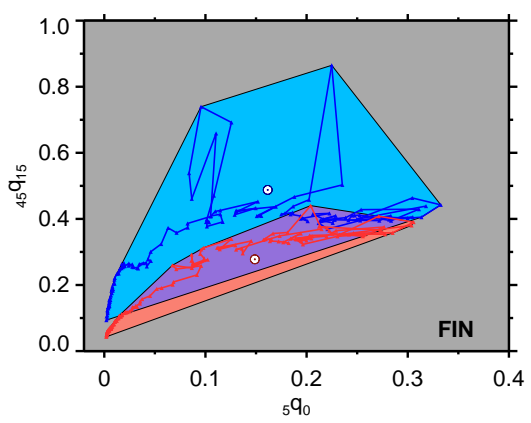

France

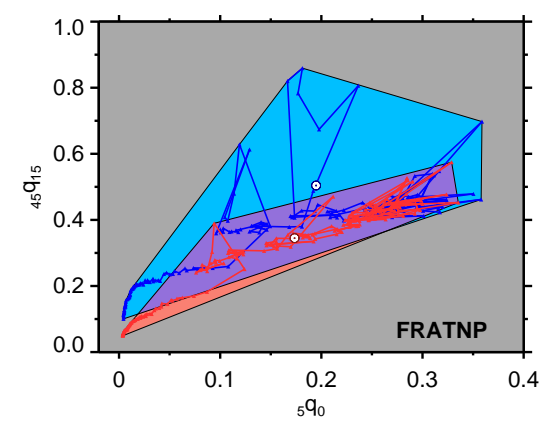



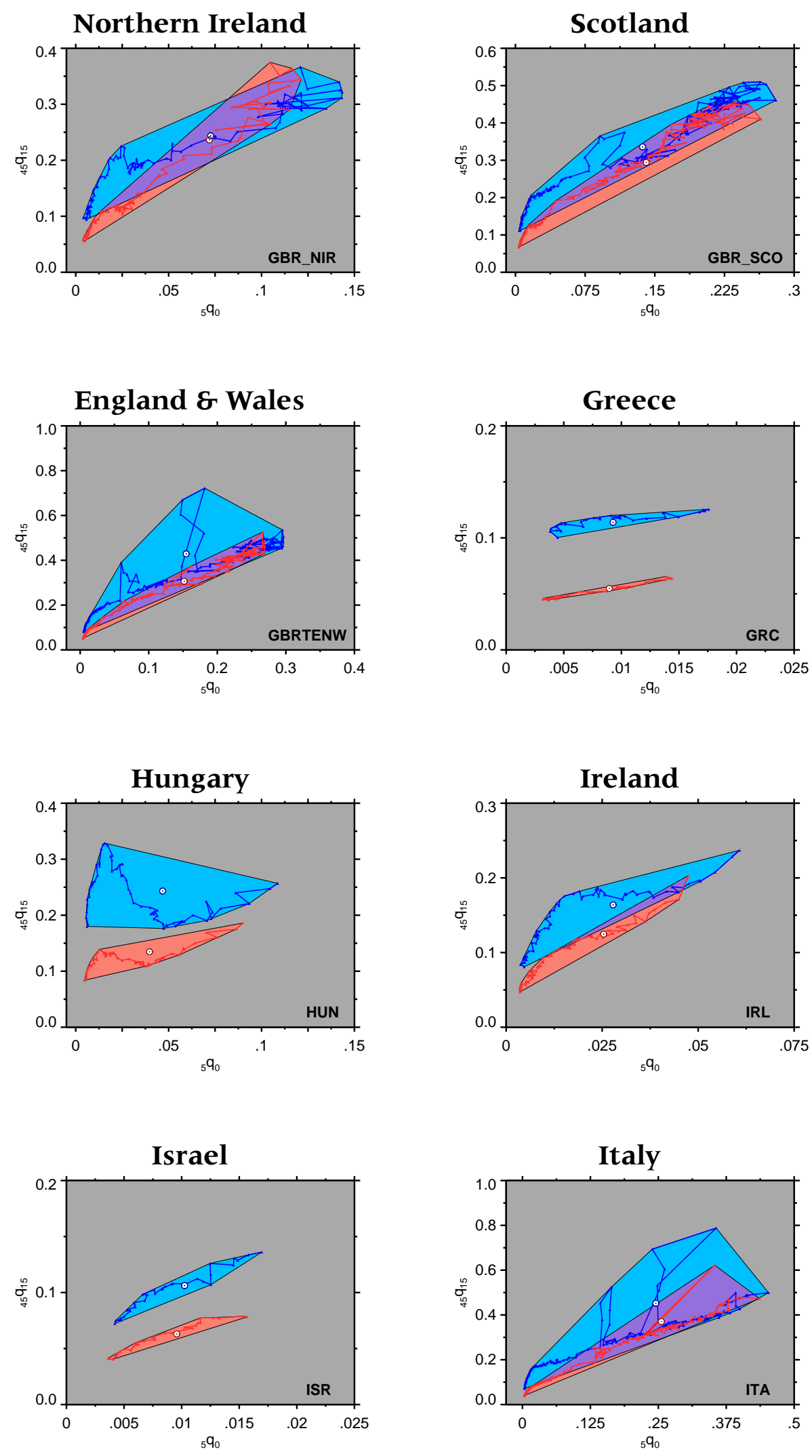

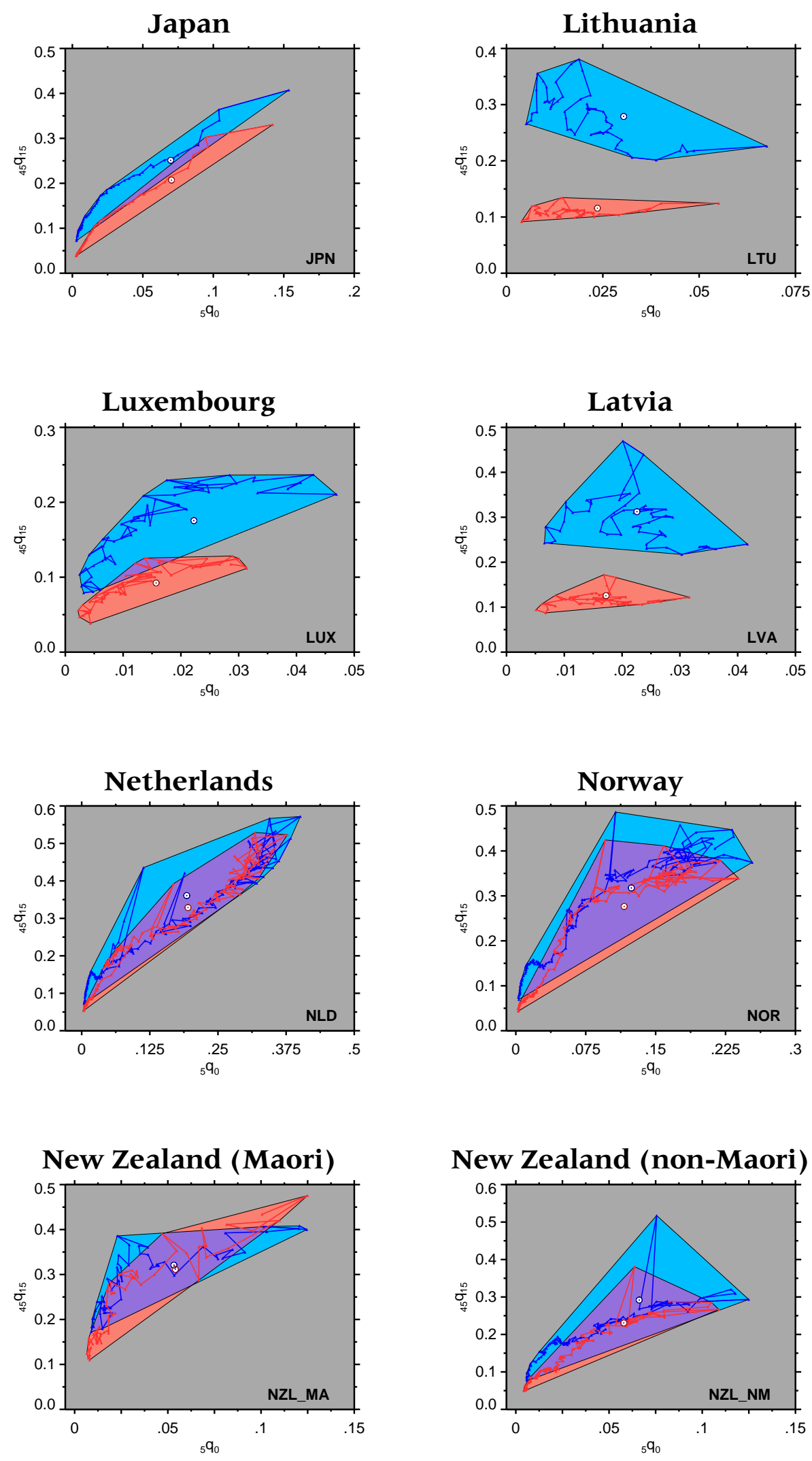

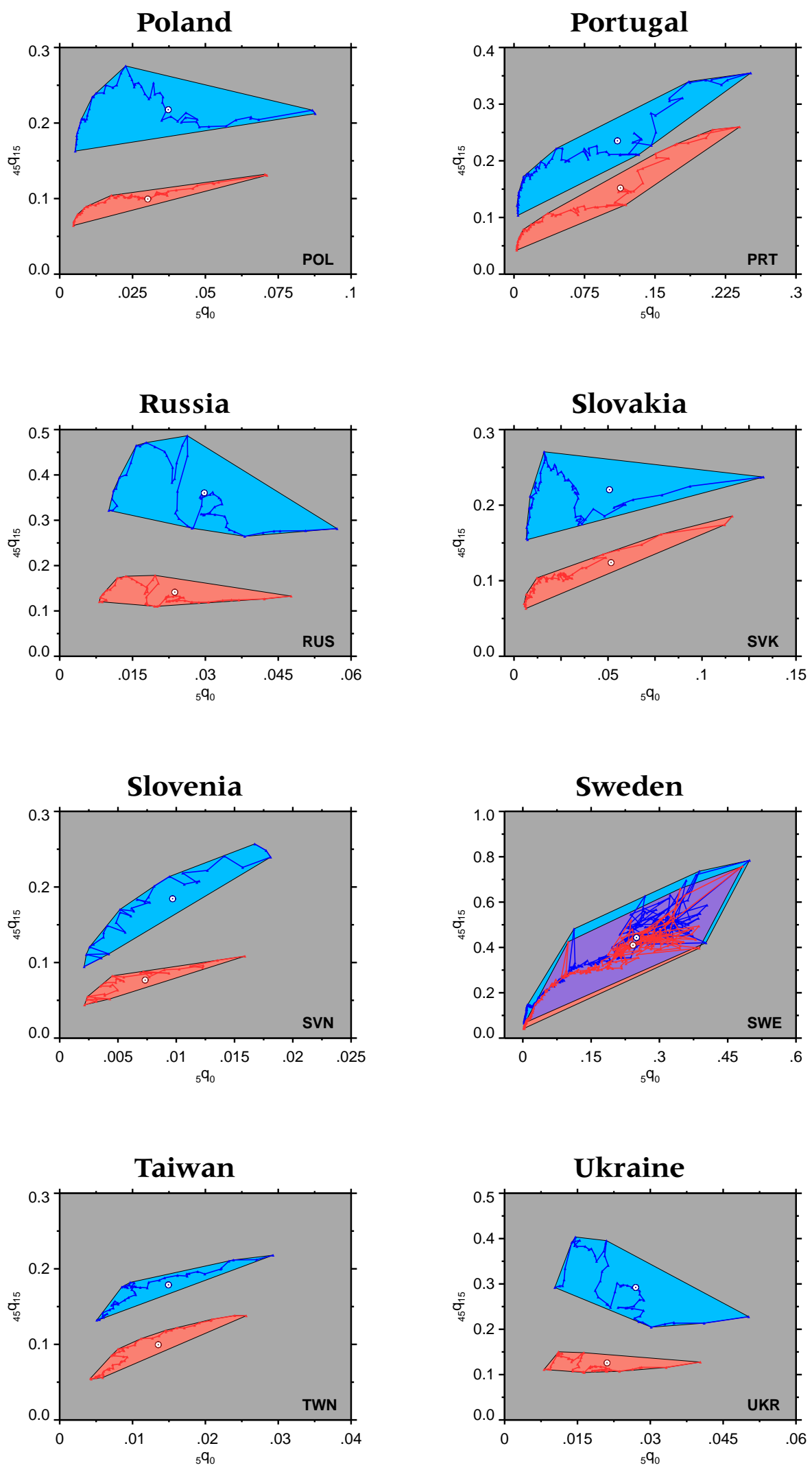


\section{Appendix II: Period-cohort hulls for all countries}

This appendix shows the period-cohort hulls for all countries apart from Finland (which is shown in figure 5 in the main text). Period hulls are colored red (females) and blue (males); cohort hulls are yellow. Where period and cohort hulls overlap, the colors are orange (females) or green (males). Period hulls are constrained to the same time range as the cohort data. Underplotted white regions are the full extent of available period data; see figure 5 caption for more details.

\section{Denmark}
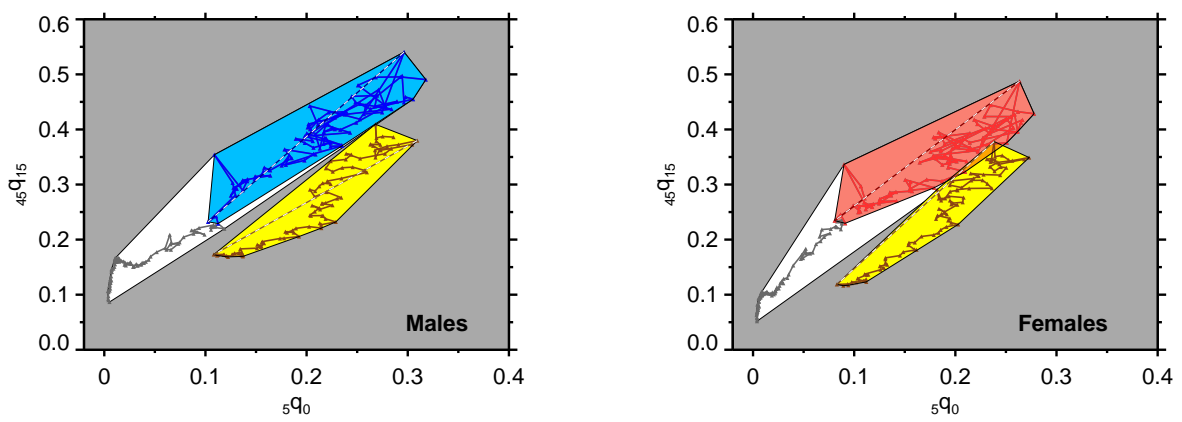

France
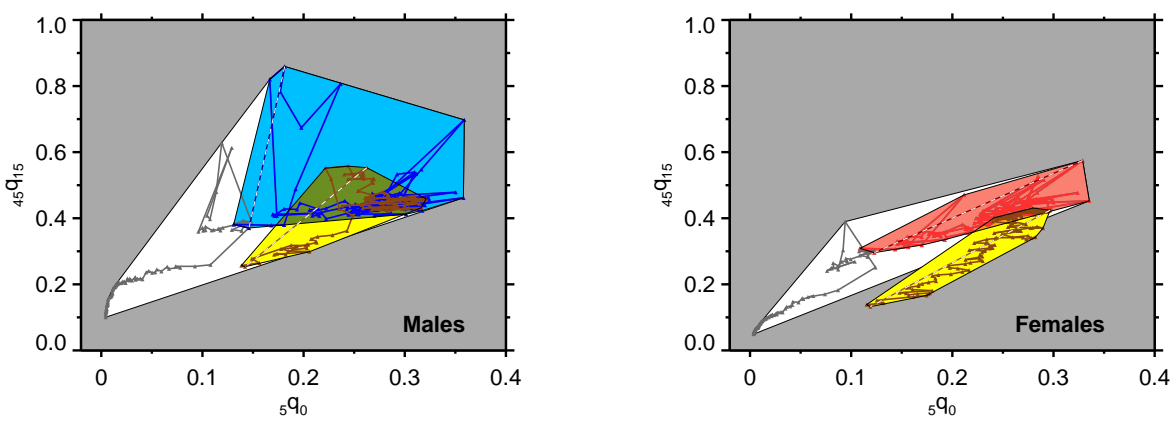


\section{Iceland}
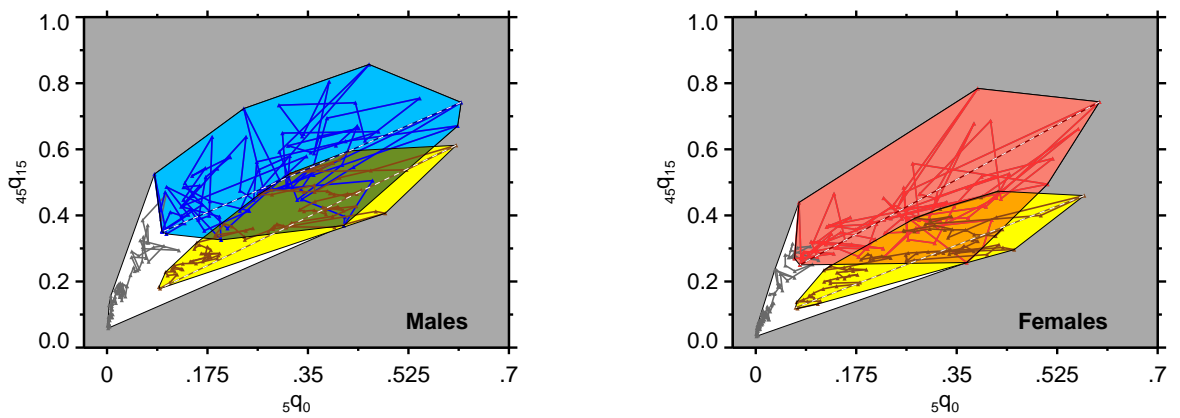

Italy
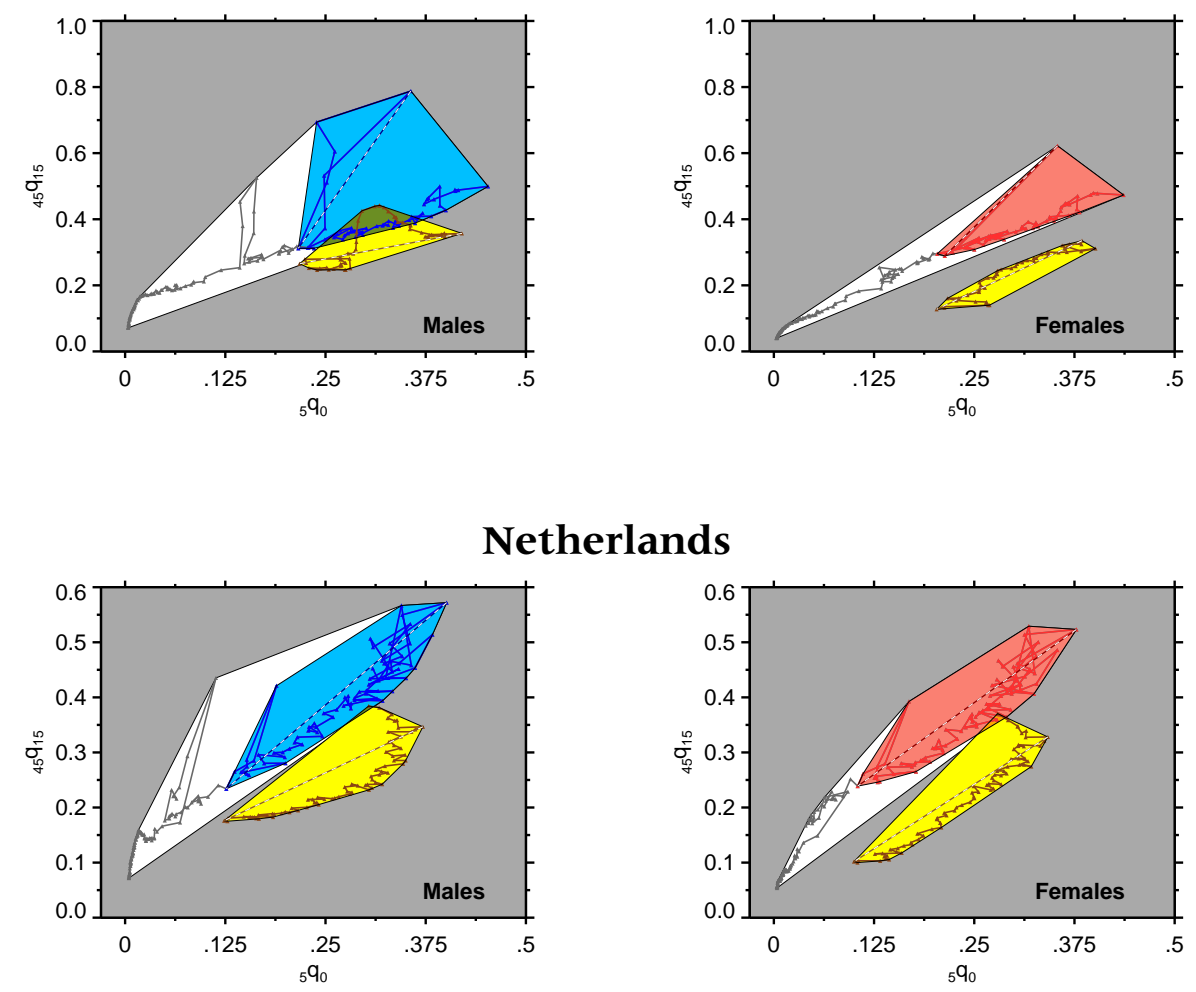

Netherlands

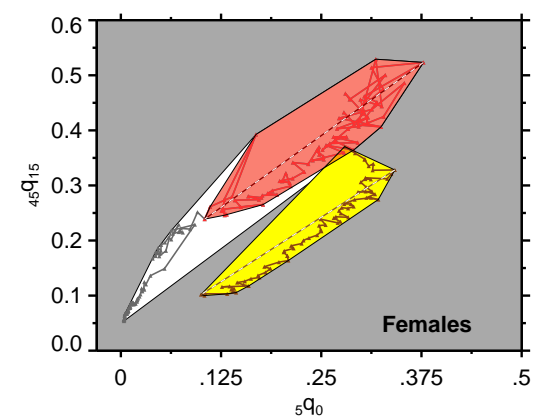




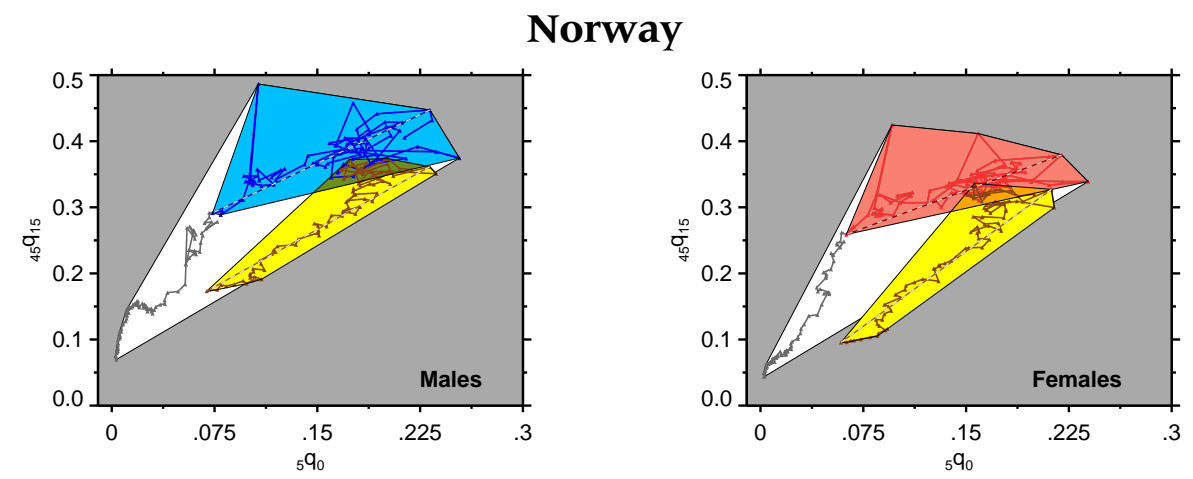

\section{Sweden}
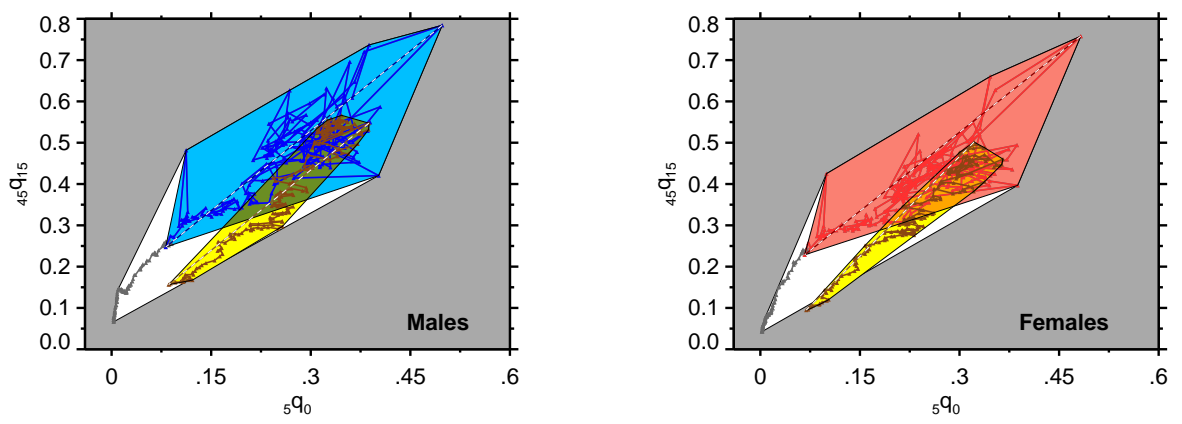

\section{Switzerland}
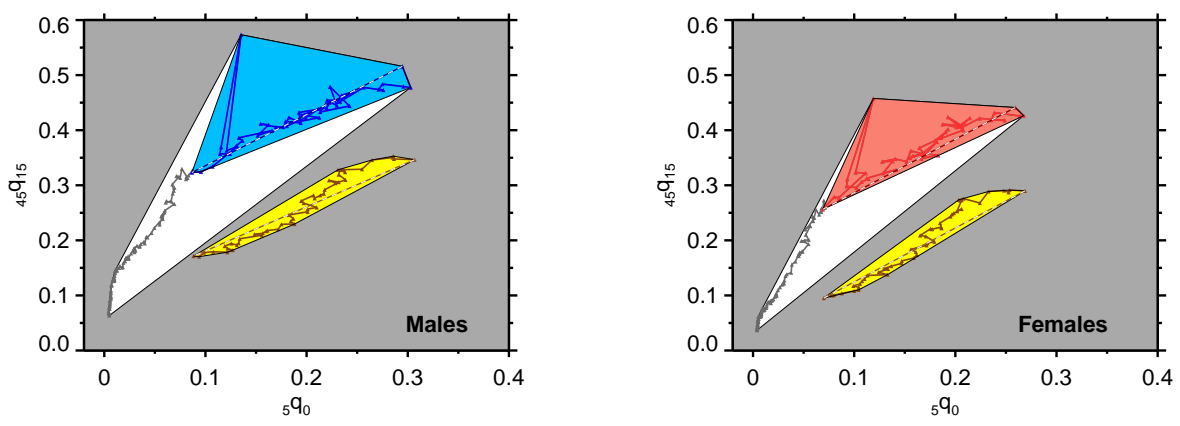


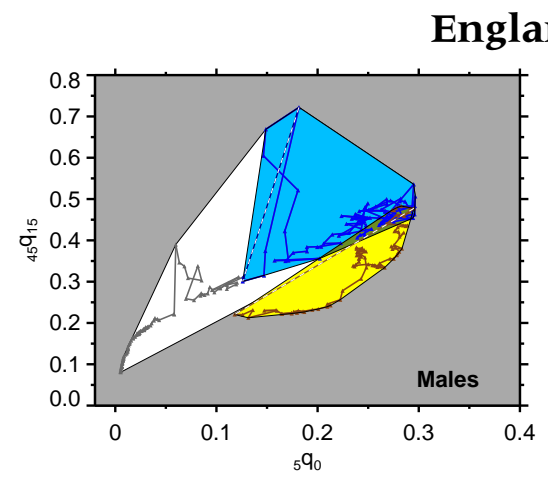

England \& Wales

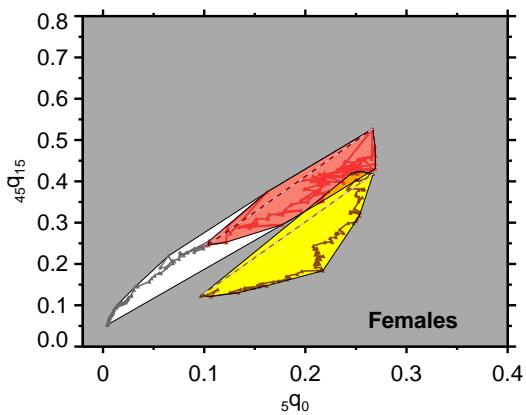

\section{Scotland}
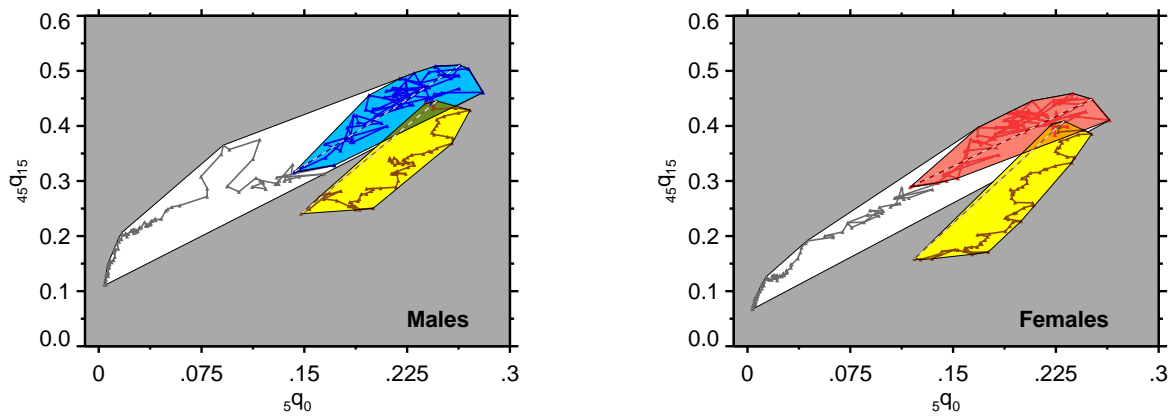

\section{Appendix III: Peeled hulls for all countries}

This appendix shows the country-peeled hulls for all countries in which peeling has an effect, apart from Iceland (which is shown in figure 7 in the main text). (Note that for Belarus, Estonia, and Russia, the difference between the master and peeled hulls is a barely-visible sliver.)

[ continues overleaf ] 

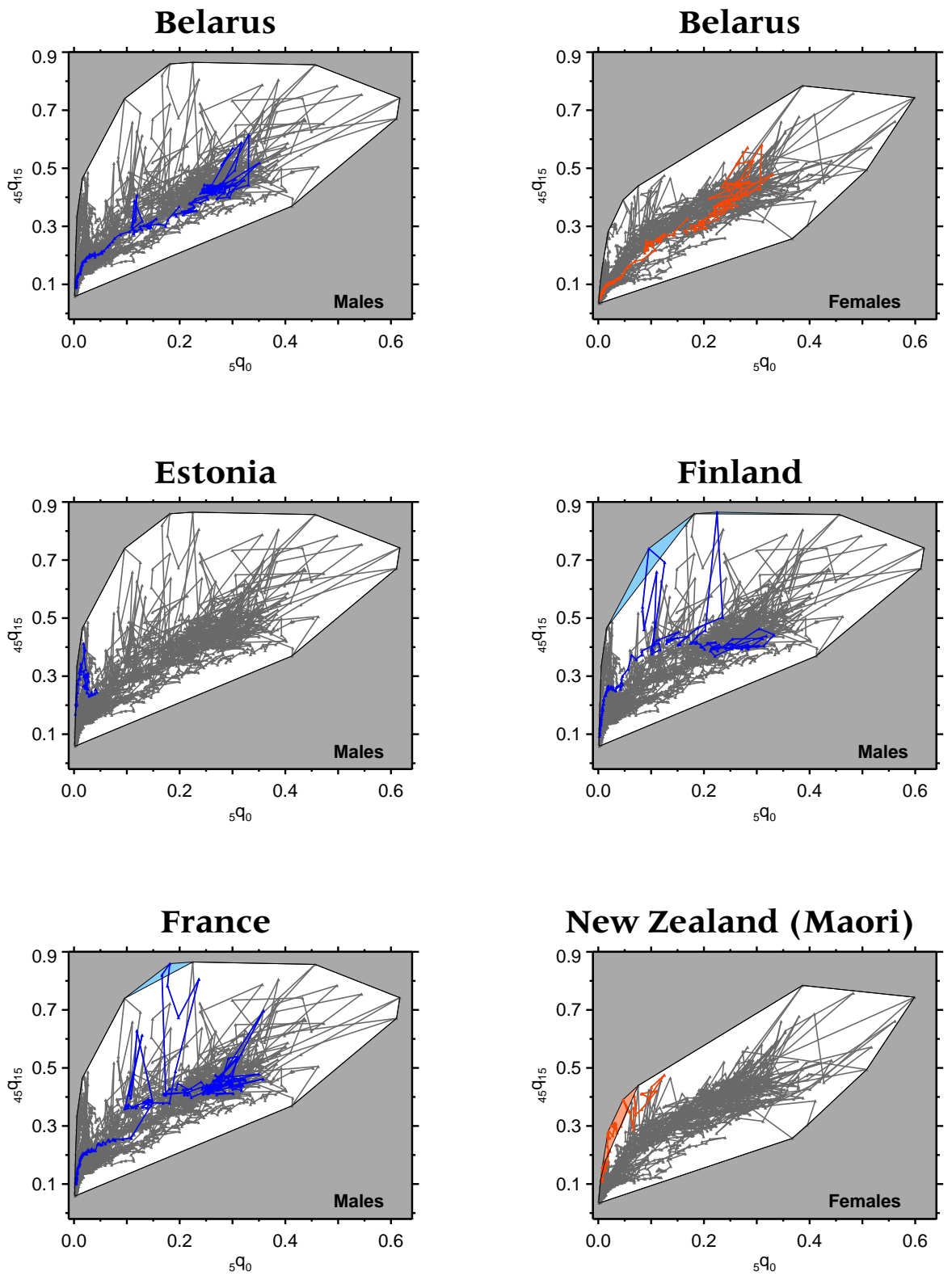


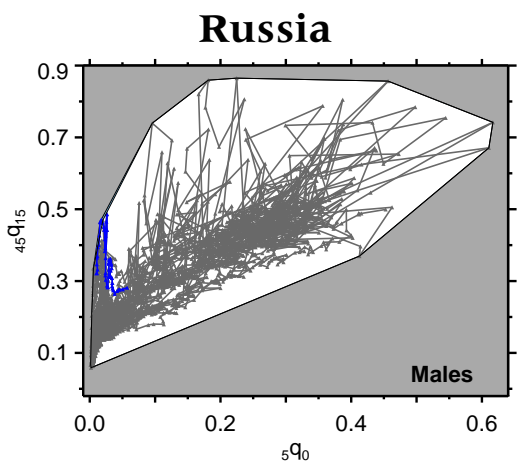

\section{Appendix IV: Country peeling, 5-year life tables}

This appendix replicates, in part, the country peeling analysis of §iii of the Results, using five-year (of time) life tables from the HMD.

[continues overleaf] 
Adult vs child mortality, by sex, for five-year (of time) life tables. Top row: This is a replication of figure 2 in the main paper. Bottom row: This is a replication of figure 7 in the main paper.
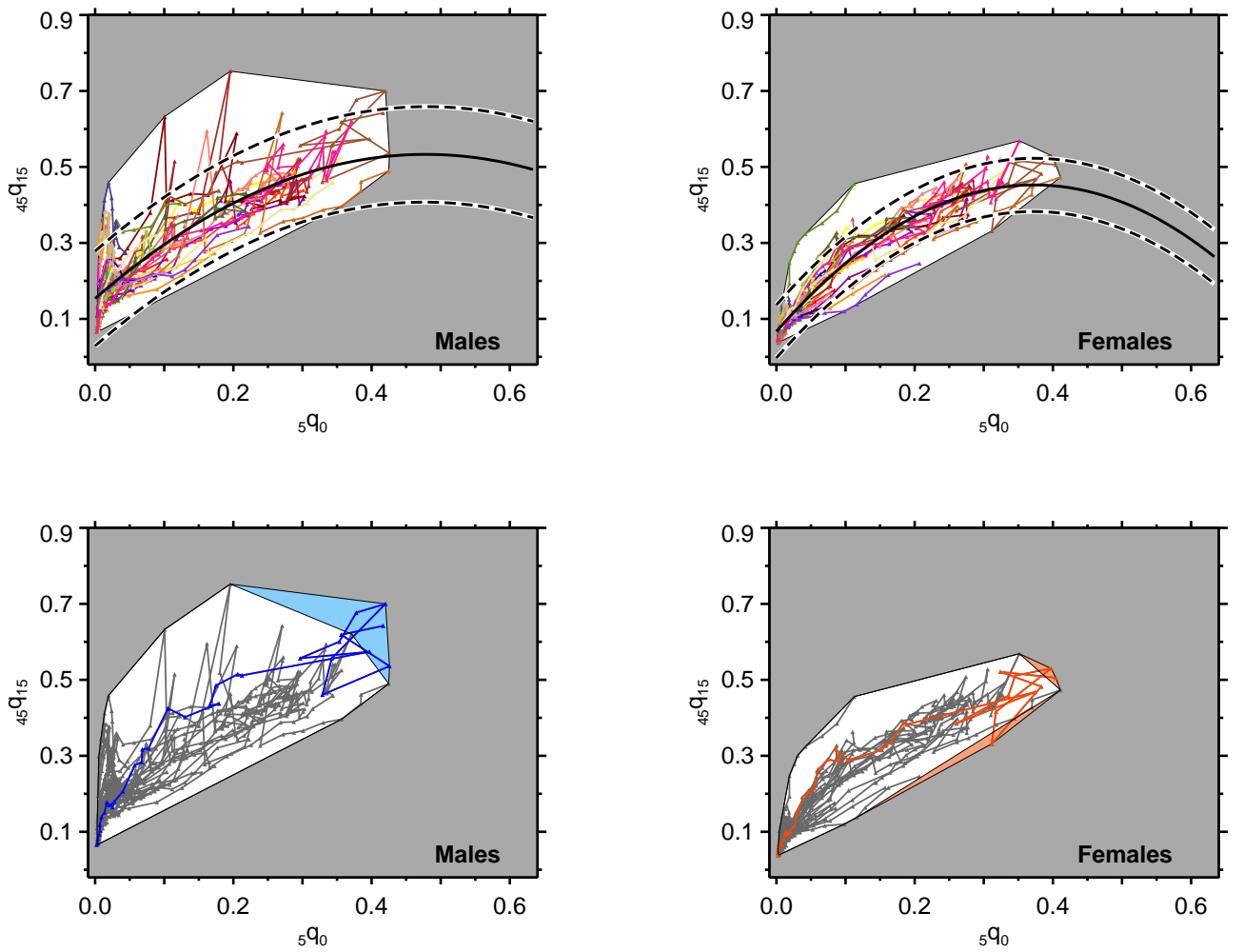

[table appears overleaf ] 
Table: Country peeling. Replication of table 4 of the main text, using five-year (of time) life tables.

\begin{tabular}{|c|c|c|c|c|c|c|}
\hline \multirow{3}{*}{$\begin{array}{l}\text { Peeled } \\
\text { country }\end{array}$} & \multicolumn{2}{|c|}{ Number of points } & \multirow{2}{*}{\multicolumn{2}{|c|}{$\begin{array}{l}\text { Ratio of peeled } \\
\text { to master hull }\end{array}$}} & \multirow{3}{*}{$\begin{array}{l}\text { Number of } \\
\text { countries in } \\
\text { peeled hull }\end{array}$} & \multirow{3}{*}{$\begin{array}{l}\text { Number of } \\
\text { sides in } \\
\text { peeled hull }\end{array}$} \\
\hline & \multirow{2}{*}{$\begin{array}{l}\text { contrib. to } \\
\text { master hull }\end{array}$} & \multirow{2}{*}{$\begin{array}{c}\text { outside } \\
\text { peeled hull }\end{array}$} & & & & \\
\hline & & & area & diameter & & \\
\hline & $(\mathrm{A})$ & (B) & $(\mathrm{C})$ & (D) & $(\mathrm{E})$ & $(\mathbf{F})$ \\
\hline \multicolumn{7}{|l|}{ Males } \\
\hline Belarus & 2 & 2 & 0.9989 & 1.0 & 8 & 13 \\
\hline Switzerland & 1 & 1 & 0.9988 & 1.0 & 6 & 11 \\
\hline Finland & 1 & 1 & 0.9800 & 1.0 & 6 & 11 \\
\hline France & 1 & 1 & 0.9066 & 1.0 & 7 & 11 \\
\hline Iceland & 3 & 6 & 0.9071 & 0.9362 & 10 & 13 \\
\hline Italy & 2 & 9 & 0.9135 & 1.0 & 6 & 10 \\
\hline Russia & 2 & 3 & 0.9834 & 1.0 & 7 & 11 \\
\hline \multicolumn{7}{|l|}{ Females } \\
\hline Belarus & 1 & 2 & 0.9994 & 1.0 & 9 & 16 \\
\hline Czech Republic & 1 & 1 & 1.0 & 1.0000 & 7 & 14 \\
\hline Finland & 1 & 1 & 1.0 & 1.0000 & 8 & 15 \\
\hline Iceland & 4 & 5 & 0.9450 & 0.9966 & 12 & 15 \\
\hline Italy & 1 & 2 & 0.9782 & 1.0 & 7 & 14 \\
\hline N.Z. (Maori) & 4 & 11 & 0.8029 & 1.0 & 11 & 16 \\
\hline Portugal & 2 & 2 & 0.9855 & 1.0 & 8 & 14 \\
\hline Sweden & 1 & 2 & 0.9420 & 0.9933 & 8 & 16 \\
\hline
\end{tabular}

